\title{
Oxygen Transport Resistance at Gas Diffusion Layer - Air Channel Interface with Film Flow of Water in a Proton Exchange Membrane Fuel Cell
}

\author{
Mustafa Koz ${ }^{\mathrm{a}}$, Satish G. Kandlikar ${ }^{\mathrm{a}, \mathrm{b}, \text { * }}$ \\ ${ }^{a}$ Microsystems Engineering, Rochester Institute of Technology, 168 Lomb Memorial Dr., Rochester, NY, \\ 14623, U.S.A. \\ ${ }^{\mathrm{b}}$ Mechanical Engineering, Rochester Institute of Technology, 76 Lomb Memorial Dr., Rochester, NY, 14623, \\ U.S.A. \\ E-mail Addresses: \\ Mustafa Koz: $\underline{\text { mxk7984@ rit.edu }}$ \\ Satish G. Kandlikar: sgkeme@ rit.edu
}

"Corresponding author:

Satish G. Kandlikar

sgkeme@rit.edu,

Mechanical Engineering, Rochester Institute of Technology, 76 Lomb Memorial Dr., Rochester, NY, 14623, U.S.A.

Telephone: +1-(585)-475-6728

Fax: +1-(585)-475-6879

1

(C) 2015. This manuscript version is made available under the Elsevier user license http://www.elsevier.com/open-access/userlicense/1.0/ 


\begin{abstract}
Water present as films on the gas diffusion layer-air channel interface in a proton exchange membrane fuel cell (PEMFC) alters the oxygen transport resistance, which is expressed through Sherwood number (Sh). The effect of multiple films along the flow length on Sh is investigated through 3D and stationary simulations. The effects of air Péclet number, non-dimensional film width, length, and spacing are studied. Using the simulation results, non-dimensional correlations are developed for local Sh within a mean absolute percentage error of $9 \%$. These correlations can be used for simulating PEMFC performance over temperature and relative humidity ranges of $20-80{ }^{\circ} \mathrm{C}$ and $0-100 \%$, respectively. Sh on the film side can be up to $31 \%$ lower than that for a dry channel, while a film may reduce the interfacial width by up to $39 \%$. The corresponding increase in transport resistance results in lowering the voltage by 5 and $8 \mathrm{mV}$ respectively at a current density of $1.5 \mathrm{~A} \mathrm{~cm}^{-2}$. However, their combined effect leads to a voltage loss of $20 \mathrm{mV}$ due to this additional mass transport resistance. It is therefore important to incorporate the additional resistance introduced by the films while modeling fuel cell performance.
\end{abstract}

\title{
Keywords:
}

Proton Exchange Membrane Fuel Cell; Interfacial Mass Transport; Water Film; Simulation; Sherwood number; Correlation

\section{Nomenclature}
Abbreviations
BPP bipolar plate
CL catalyst layer
FD fully developed
GDL gas diffusion layer
ICE internal combustion engine
MAPE mean absolute percentage error
PEMFC proton exchange membrane fuel cell
TPCL triple-phase contact line 


\section{Variables}

A $\quad$ area

$a, b, c \quad$ coefficients of correlations

C oxygen molar concentration

$D_{\text {O2-air }} \quad$ molar oxygen diffusivity in air

$D_{\text {O2-GDL }}$ molar oxygen diffusivity in the gas diffusion layer

$d_{\mathrm{h}} \quad$ hydraulic diameter

F air drag force on a film

$F_{\mathrm{c}} \quad$ Faraday's constant

Height

$h_{\mathrm{M}} \quad$ mass transfer coefficient

I identity matrix

$i \quad$ current density

$j \quad$ magnitude of oxygen molar flux

L length

$N \quad$ number of films in the air channel

$\mathrm{Nu} \quad$ Nusselt number

Pe Péclet number

Po Poiseuille number

p air pressure

$r \quad$ semi-principle axis length of an ellipsoid

$R_{\mathrm{u}} \quad$ universal gas constant

Sc $\quad$ Schmidt number

Sh Sherwood number

$T \quad$ temperature

u velocity vector

$u, v, w \quad$ velocity components

V voltage

W air channel width

We Weber number 
$\mathbf{x}$ spatial coordinate vector

$x, y, z \quad$ spatial coordinate components

$\Delta x \quad$ distance in the flow direction

\section{Greek}

$\begin{array}{ll}\Pi & \text { non-dimensional group } \\ \theta & \text { droplet static contact angle } \\ \mu & \text { dynamic viscosity of air } \\ \xi & \text { droplet-blocked portion of the channel cross sectional area } \\ \rho & \text { air mass density } \\ \sigma & \text { air-water surface tension }\end{array}$

\section{Subscript}

$\infty \quad$ asymptotic value

ac repetitive unit area under a channel and land

ad adhesion

av averaged

ch channel based

D drag force along the flow direction

eff effective

f film

FD fully developed

int interfacial

m mean

$n \quad$ droplet number in the flow direction

side side wall of the channel

st static contact angle

top top wall of the channel

$x \quad$ flow direction specific

wet droplet-covered portion of the GDL-channel interface 


\section{Superscript}

$\begin{array}{ll}* & \text { non-dimensional } \\ T & \text { transpose }\end{array}$

\section{Introduction}

Proton exchange membrane fuel cells (PEMFCs) are electrochemical engines that are environmentally friendly in contrast to internal combustion engines (ICEs) that are used in automotive applications. Hydrogen is used as the fuel and water is the sole byproduct. Efficient liquid water removal is a key factor to increase the PEMFC efficiency and reduce the cost. The design of PEMFCs has been evolving to match the low cost offered by current ICEs. As a part of the PEMFC design considerations, oxygen transport resistance needs to be taken into account.

As oxygen is transported from air channels toward the cathode catalyst layer, it encounters two major transport resistances: at the interface of the gas diffusion layer (GDL) and the air channel, and the GDL itself. The transport resistance in the GDL is a function of its water saturation which has been studied through numerical models [1-4], visualization techniques [5,6], and ex-situ experiments [7,8]. The interfacial transport resistance is less investigated. It has been shown that presence of liquid water in the channels adversely affects the transport by blocking the available interfacial area [9]. The blocked interfacial area has been characterized though optical visualization of operational PEMFCs [10,11] and numerical simulations [12,13]. The flow of air and water introduces different flow patterns in the channels, including droplet on the GDL surface, slug flow, film flow and mist flow. The GDL surface covered by liquid water is not available for oxygen transport, and it changes the diffusion characteristics of oxygen into the GDL in the regions not covered by water.

The oxygen concentration drop at the GDL-air channel interface can be expressed through the Sherwood number (Sh). This resistance is not well investigated in air channels with two-phase flow as explicitly mentioned by Casalegno et al. [1]. Sh has therefore been assumed to be constant throughout the length of the air channels in simplified PEMFC performance models [14-19]. For single-phase fully developed flow in channels, Sh corresponds to the fully developed Nusselt number corresponding to the same channel cross section with equivalent heat transfer boundary conditions. However, droplets, films, and slugs exist during two-phase flow and prevent fully developed conditions. Slugs completely block the interfacial transport. Droplets and films do not completely block the air flow but alter the oxygen transport in the open areas of the GDL-channel interface. 
Liquid films refer to water features that do not span the entire width and height of the channel cross section. They differ from droplets by not having a spherical shape and having a length in the direction of the air flow. Koz and Kandlikar characterized Sh for the cases where the GDL-air channel interface is covered with droplets [20,21]. However, films have been recognized to occur more frequently in PEMFC air channels [10,11]. The range of conditions leading to the formation of films have been demonstrated numerically by LorenziniGutierrez et al. [12] and Zhu et al. [13], and experimentally by Lee and Ito [22] and Cheah et. al. [23]. This study extends the authors' earlier work on droplets to simulate the oxygen transport resistance under film flow conditions, which are more prevalent in the air channels.

The interfacial transport resistance of oxygen is numerically investigated in the presence of water films. These films are sequentially placed on alternating sides of the channel, assumed to be attached to channel surfaces and are represented as solid obstructions in single-phase air flow. The shapes of these obstructions are derived from the experimental observations of water films [22-24]. In order to ensure the presence of stationary films, a detachment analysis is performed as follows: i) Air drag forces are numerically calculated. ii) Adhesion forces are theoretically calculated. iii) The resulting drag and adhesion forces are compared. The conditions that lead to detachment are not used to characterize Sh as the film would be removed by the air flow.

The input parameters in this study are film length, width, and spacing, and inlet air velocity, which reflects the changes in current density and stoichiometry. Down-the-channel variations of Sh are reported on the side of a film and its wake and are expressed with two non-dimensional mathematical correlations. The changes in Sh are compared against the reduction of interfacial area due to film blockage. The effect of variations in Sh on local cell performance is analyzed by calculating and comparing voltage losses that correspond to various sets of input parameters at a constant current density.

\section{Methodology for Numerical Simulations}

\subsection{Introduction to the Methodology of Numerical Simulations}

Simulations were performed in a single air channel that complies with the U.S. Department of Energy performance targets [25]. Multiple film-shaped obstructions were placed on alternating sides of the channel. The shape of the obstructions was chosen to mimic experimentally observed stationary film shapes in the available literature. The rationale behind choosing stationary films is the following: Liquid films were shown to take a longer time to grow in the channel than the time to depart. Pressure readings and visualization from ex- 
situ experiments by Colosqui et al. [26], Shah and Kandlikar [27], and Hellstern et al. [28] quantify the duration of attachment and motion of a water feature. For instance, Hellstern et al. showed that 19 seconds is required for a slug to form and only 3 seconds to exit the channel [28]. This experimental setup replicates in-situ conditions by placing a GDL in an acrylic channel. The water and air flows rate of $25 \mu \mathrm{L} \mathrm{min}{ }^{-1}$ and $9 \mathrm{~mL} \mathrm{~min}^{-1}$, respectively and correspond to approximately $3 \mathrm{~A} \mathrm{~cm}^{-2}$ and an air stoichiometry of 4.5 . Based on the aforementioned results, the steady state simulations in the current study can help the audience predicting fuel cell performance when water films are in the stage of growth.

The growth of a water film takes seconds as shown by the results mentioned above. The air flow around the film complies with this growth very fast. The viscous diffusion time scale is calculated for the channel hydraulic diameter in this work, $d_{\mathrm{h}}=0.51 \mathrm{~mm}$ and kinematic viscosity, $v=\mu / \rho=16.253 \times 10^{-6} / 0.828=19.629 \times 10^{-6}$. The time scale result is $t=d_{\mathrm{h}}{ }^{2} / v=0.013 \mathrm{~s}$. This is three orders of magnitude smaller than the growth time (19 s) of a water feature as reported by Hellstern et al.[28].

The diffusion of oxygen through these obstructions can be neglected since the diffusion resistance of liquid water films is four orders of magnitude larger than that of air: $D_{02-H 2 O}$ and $D_{02-a i r}$ are $0.24 \times 10^{-4}[29]$ and 0.31 $\mathrm{cm}^{2} \mathrm{~s}^{-1}[21]$. The length of a film $\left(L_{\mathrm{f}}\right)$ was defined such that when it is zero, the film transforms into a droplet on the channel side wall. A non-zero length corresponds to a droplet that is elongated in the flow direction. The width of a film $\left(W_{\mathrm{f}}\right)$ indicates the largest distance that the film covers on the top channel wall along the direction of channel width. In the presence of a film, the GDL-air channel interface is partially covered and thus referred to as wet interface width ( $W_{\text {wet }}$ ). The distance between the films is assumed to be uniform $\left(\Delta x_{\mathrm{f}}\right)$ and is measured from the closest points of two adjacent films. The inlet air velocity $\left(u_{\mathrm{m}}\right)$ reflects the imposed current density $(i)$ and stoichiometry.

The simulations numerically calculate the local Sh profile in the vicinity of films. Temperature changes are minimal in the vicinity of the film compared to the entire electrochemically active area length. This allows a given simulation to use a constant temperature for the air properties in the governing equations. The effect of temperature on Sh was investigated by conducting simulations at different air temperatures. Firstly, Sh correlations were developed at a temperature $(T)$ and relative humidity $(\mathrm{RH})$ of $80^{\circ} \mathrm{C}$ and $100 \%$, respectively. Secondly, the correlations were tested against simulation results at $20^{\circ} \mathrm{C}$ and $0 \% \mathrm{RH}$ in Section 3.4.4.

Fully humidified air properties of mass density $(\rho)$ and dynamic viscosity $(\mu)$ were calculated with the correlations provided by Tsilingiris [30]. Temperature is input in ${ }^{\circ} \mathrm{C}$.

$$
\rho=1.293-5.538 \times 10^{-3} T+3.860 \times 10^{-5} T^{2}-5.254 \times 10^{-7} T^{3}
$$


$\mu=1.716 \times 10^{-5}+4.722 \times 10^{-8} T-3.663 \times 10^{-10} T^{2}+1.873 \times 10^{-12} T^{3}-8.050 \times 10^{-14} T^{4}$

Oxygen diffusivity in the air $\left(D_{O 2-a i r}\right)$ was approximated with Wilke's formula [31] by averaging component diffusivities with respect to their molar fractions $(\omega)$.

$$
D_{02-a i r}=\frac{1-\omega_{\mathrm{O} 2}}{\frac{\omega_{\mathrm{N} 2}}{D_{\mathrm{O} 2-\mathrm{N} 2}}+\frac{\omega_{\mathrm{H} 22}}{D_{\mathrm{O} 2}-\mathrm{H} 2 \mathrm{O}}}
$$

For fully humidified air, the molar fraction of vapor in air is $\left.\omega_{\mathrm{H} 2 \mathrm{O}}=p_{\mathrm{H} 2 \mathrm{O}, \text { sat }}\right\rfloor p_{\text {air. }}$. This was calculated based on the vapor saturation pressure formula below provided by Mench [32]. The temperature is in the unit of ${ }^{\circ} \mathrm{C}$. The remaining dry air was assumed to have an oxygen - nitrogen ratio of $21-79 \%$, respectively.

$$
p_{\text {sat }}=-2846.4+411.24 T-10.554 T^{2}+0.16636 T^{3}[\mathrm{~Pa}]
$$

The diffusivity correlation for air components is provided by Fuller et al. [33]. The units for temperature (T), molecular weight $(M)$, and pressure $(p)$ are $\mathrm{K}, \mathrm{g} \mathrm{mol}^{-1}$, and atm, respectively. Diffusion volumes of simple molecules $(v)$ are provided in the same article [33].

$$
D_{A B}=\frac{10^{-3} T^{1.75}\left(\frac{1}{M_{A}}+\frac{1}{M_{B}}\right)^{0.5}}{p\left[v_{A}^{1 / 3}+v_{B}^{1 / 3}\right]^{2}}\left[\mathrm{~cm}^{2} \mathrm{~s}^{-1}\right]
$$

With the aforementioned air properties, Schmidt number $\left(\mathrm{Sc}=\mu \rho^{-1} \underline{D}_{\text {o2-air }}^{-1}\right)$ was calculated. When simulating the effect of temperature, $\mathrm{Sc}$ was varied to represent changes in temperature and other nondimensional input parameters were kept constant.

The density $(\rho)$ and dynamic viscosity $(\mu)$ of the air and the diffusivity of oxygen in the air $\left(D_{\text {O2-air }}\right)$ were kept constant at $0.828 \mathrm{~kg} \mathrm{~m}^{-3}, 16.253 \mu \mathrm{Pa} \mathrm{s}$, and $0.310 \mathrm{~cm}^{2} \mathrm{~s}^{-1}$, respectively for the simulations that led to the correlations. The input parameters were non-dimensionalized with the hydraulic diameter of the channel, 0.51 $\mathrm{mm}$. The film width and length and the inlet air velocity were expressed as non-dimensional film width $\left(W_{\mathrm{f}}^{*}\right)$ and length $\left(L_{\mathrm{f}}^{*}\right)$ and Péclet number $(\mathrm{Pe})$, respectively. The air properties $\left(\rho, \mu\right.$, and $\left.D_{\mathrm{O} 2 \text {-air }}\right)$ were expressed as the Schmidt number $\left(\mathrm{Sc}=\mu \rho^{-1} D_{\text {O2-air }}^{-1}\right)$.

\subsection{Geometry}

The numerical simulations were conducted in a single air channel with single-phase air flow and filmshaped obstructions referred to as films henceforth. The authors coupled the air channel with a GDL in an earlier study [34]. This coupling allowed the investigation of oxygen diffusion underneath the flow field ribs. The same Sherwood number was obtained through simulations when the air channel was simulated alone and coupled with the GDL. The authors also studied the effect droplet-induced convection through a GDL on Sh 
profile and found no significant effect even at the largest possible droplet size [34]. Since the films in this study constrict channel cross section the same amount as those that were analyzed earlier, the effect of film-induced convection can be neglected. Therefore, the flow is considered to be only in the channel. Fig. 1 shows the channel and flow field (FF) dimensions. The electrochemically active area $\left(A_{\mathrm{ac}}\right)$ is a repeating pattern that covers the width of the GDL-air channel interface and a bipolar plate land (rib) width. The land width ( $W_{\text {land }}$ ), channel width $\left(W_{\mathrm{ch}}\right)$, and channel height $\left(H_{\mathrm{ch}}\right)$ were selected to be $0.50 \mathrm{~mm}, 0.70 \mathrm{~mm}$, and $0.40 \mathrm{~mm}$, respectively [25]. The active area length $\left(L_{\mathrm{ac}}\right)$ was selected as $183.00 \mathrm{~mm}$ [25] for calculating the superficial air velocity that corresponds to a current density.

Fig. 1a shows multiple films placed in a row and on alternating sides $\left(y_{\mathrm{f}}=0\right.$ and $\left.y_{\mathrm{f}}=W_{\mathrm{ch}}\right)$ in the channel. These films are numbered in the flow direction with the variable, $n$. The Sh profile changes in the flow direction and ultimately merges into a repeating pattern after a certain number of films. The total number of films $(N)$ was selected to be large enough for the results not to differ significantly in the flow direction by the last film. It was found that the required number of films for the Sh profile to merge into a repeating pattern is dependent on $\Delta x_{\mathrm{f}}$. Hence, $N$ was selected based on each value of $\Delta x_{\mathrm{f}}$.

Both single and multiple film scenarios were studied. A film was represented by a combination of the following basic geometrical shapes: spheres, cylinders, and a rectangular prism. This convention represents the top ( $-z$ direction) and cross sectional (-x direction) views of air channels observed by Gopalan and Kandlikar [24], Lee and Ito [22], and Cheah et al. [23]. This geometry was subtracted from the rectangular-prism-shaped channel to simulate single-phase air flow.

Fig. 1a depicts the building components of a film with dotted lines. $W_{\mathrm{f}}$ was varied from 0.20 to $0.50 \mathrm{~mm}$ (corresponding to non-dimensional values of 0.39 to 0.98 , respectively). When the film length $\left(L_{\mathrm{f}}\right)$ is zero, the film becomes a droplet at the channel corner. In this work, droplets emerging from channel corners are also analyzed as a starting point for films and are referred to as films with zero length. Non-zero $L_{\mathrm{f}}$ values were 1.00 , 2.00 , and $5.00 \mathrm{~mm}$ (non-dimensionally: 1.96, 3.92, and 9.80, respectively). The uniform spacing between the films $\left(\Delta x_{\mathrm{f}}\right)$ were $1.00,2.00$, and $5.00 \mathrm{~mm}$ (non-dimensionally: 1.96, 3.92, and 9.80, respectively).

The spheres and the cylinder which were in contact with the GDL-air channel interface were truncated in such a way that the apparent static contact angle $\left(\theta_{\mathrm{st}, \mathrm{GDL}}\right)$ is $147^{\circ}$. The GDL contact angle was selected as a representative value of the GDLs characterized by Gopalan and Kandlikar [35] and Das et al. [36]. Graphite was selected as the channel wall material. The advancing and receding contact angles on a graphite plate were measured to be $85^{\circ}$ and $61^{\circ}$ respectively [35]. The static contact angles on the graphite channel side $\left(\theta_{\mathrm{st}, \text { side }}\right)$ and 
top walls $\left(\theta_{\text {st,top }}\right)$ were assumed to be $90^{\circ}$. The static angles were used to generate the film-shaped obstructions. The advancing and receding angles were used to calculate the contribution of side and top walls to the film adhesion force. The film width and the aforementioned static contact angle on the GDL leads to an interfacial width coverage $\left(W_{\text {wet }}(x)\right)$ as defined in Eq. (6).

$$
W_{\text {wet }}(x)=\left\{\begin{array}{c}
\left(x_{\mathrm{f}, n} \leq x \leq x_{\mathrm{f}, n}+L_{\mathrm{f}}\right) \rightarrow W_{\mathrm{f}} \cos \left(\pi \frac{\theta_{\mathrm{st}, \mathrm{GDL}}-90^{\circ}}{180}\right) \\
\text { Else } \rightarrow 0
\end{array}\right.
$$

\subsection{Post-Processing and Non-Dimensionalization}

The objective of this work is to find the oxygen concentration drop $(\Delta C)$ for a given magnitude of oxygen flux $(j)$ at the GDL-air channel interface. Non-dimensional variables were used to reduce the number of simulations and obtain correlations that are applicable to a wider range of conditions. Buckingham Pi Theorem [37] was used to obtain the following non-dimensional variables: Schmidt number $\left(\mathrm{Sc}=\mu \rho^{-1} D_{\mathrm{O} 2 \text {-air }}{ }^{-1}\right)$, nondimensional film width $\left(W_{\mathrm{f}}^{*}=W_{\mathrm{f}} d_{\mathrm{h}}^{-1}\right)$, non-dimensional film length $\left(L_{\mathrm{f}}^{*}=L_{\mathrm{f}} d_{\mathrm{h}}^{-1}\right)$, non-dimensional film spacing $\left(\Delta x_{\mathrm{f}}{ }^{*}=\Delta x_{\mathrm{f}} d_{\mathrm{h}}{ }^{-1}\right)$, Péclet number $\left(\mathrm{Pe}=d_{\mathrm{h}} u_{\mathrm{m}} D_{\mathrm{O} 2 \text {-air }}{ }^{-1}\right)$, and Sherwood number $\left(\mathrm{Sh}=j d_{\mathrm{h}} \Delta C^{-1} D_{\mathrm{O} 2 \text {-air }}{ }^{-1}\right)$.

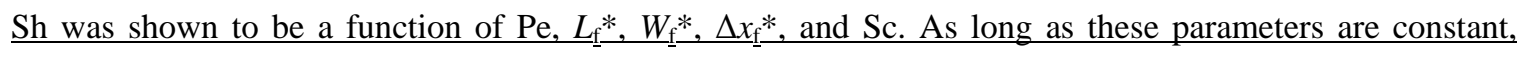
$\underline{\text { simulating Sh at different current densities always leads to the same result. Mapping current densities to Péclet }}$ $\underline{\text { numbers was performed in this study to obtain a parametric range of Pe. As a result, the users of correlations can }}$ obtain the Sh by using Péclet number first and then, find the oxygen concentration drop at the desired local current density.

For the numerical evaluation of Sh, the local oxygen transport resistance is calculated at every point on the GDL-air channel interface. For a given $j$, the corresponding $\Delta C$, is the difference between the $\mathrm{O}_{2}$ concentration at the interface $\left(C_{\mathrm{int}}=C(z=0)\right)$ and the mean value at a channel cross section $\left(C_{\mathrm{m}}\right)$. This resistance is expressed with the mass transfer coefficient $\left(h_{\mathrm{M}}\right)$.

$$
\begin{gathered}
h_{\mathrm{M}}(x, y)=j \Delta C^{-1}=j\left(C_{\mathrm{m}}-C_{\mathrm{int}}\right)^{-1} \\
C_{\mathrm{m}}(x)=\frac{\int \text { Channel } c u \mathrm{~d} A}{\int_{\text {cross section section }}^{\text {Channel }} u \mathrm{~d} A}
\end{gathered}
$$

In simulations, $h_{\mathrm{M}}$ is zero at the portion of the GDL-channel interface that is covered by a film: $W_{\text {wet }}(x)$. Eq. (9) presents an effective mass transfer coefficient ( $\left.h_{\mathrm{M}, \text { eff }}\right)$. This variable assigns a value of $h_{\mathrm{M}}$ everywhere on the interface $(z=0)$.

$$
h_{\mathrm{M}, \mathrm{eff}}(x, y)=\left\{\begin{array}{c}
\text { Dry Interface } \rightarrow h_{\mathrm{M}} \\
\text { Wet Interface } \rightarrow 0
\end{array}\right.
$$


In Eq. (10), the variations of $h_{\mathrm{M}, \mathrm{eff}}(x, y)$ were averaged along the dry GDL-channel interface width $\left(W_{\mathrm{ch}^{-}}\right.$ $\left.W_{\text {wet }}(x)\right)$ into the dry-region-averaged mass transfer coefficient $\left(\overline{h_{\mathrm{M}}}(x)\right)$. The resulting variable only varies in the flow direction.

$$
\overline{h_{\mathrm{M}}}(x)=\frac{1}{W_{\mathrm{ch}}-W_{\mathrm{wet}}} \int_{y=0}^{W_{\mathrm{ch}}} h_{\mathrm{M}, \mathrm{eff}} \mathrm{d} y
$$

The dependency of $\overline{h_{\mathrm{M}}}$ on $d_{\mathrm{h}}$ and $D_{\mathrm{O} 2 \text {-air }}$ was eliminated with the use of Sherwood number $(\mathrm{Sh}=$ $\left.\overline{h_{\mathrm{M}}} d_{\mathrm{h}} D_{\mathrm{O} 2-\text { air }}^{-1}\right)$. The loss of interfacial area due to coverage by water features leads to an increase in the net mass transport resistance which has been integrated into Sh. A variation of Sh is defined as the effective $\mathrm{Sh}\left(\mathrm{Sh}_{\mathrm{eff}}\right)$ which can be related to Sh as shown in Eq. (11). For simplified PEMFC performance models that incorporate the effects of films, the use of $\mathrm{Sh}_{\mathrm{eff}}$ instead of $\mathrm{Sh}$ is important to account for the loss of interfacial area.

$$
\operatorname{Sh}_{\mathrm{eff}}(x)=\operatorname{Sh}(x)\left[W_{\mathrm{ch}}-W_{\text {wet }}(x)\right] W_{\mathrm{ch}}^{-1}
$$

\subsection{Governing Equations for the Numerical Model}

In this numerical study, convective mass transport was modeled with a steady-state and 3D formulation of the governing equations. Air was assumed to be incompressible. Continuity and Navier-Stokes equations are shown in Eqs. (12) and (13) respectively and were solved simultaneously. Following their solution, the oxygen transport was simulated by the advection-diffusion equation as presented in Eq. (14). The diffusive component was modeled by Fick's law, a simplified formulation of the Maxwell-Stefan equation. This simplification is justifiable for a dilute species as stated by Krishna and Wesselingh [38]. Since oxygen had a molar fraction of 0.11 at the channel inlet, Fick's law could be utilized.

$$
\begin{gathered}
\rho \nabla \cdot \mathbf{u}=0 \\
\rho(\mathbf{u} \cdot \nabla) \mathbf{u}=\nabla \cdot\left[-p \mathbf{I}+\mu\left(\nabla \mathbf{u}+(\nabla \mathbf{u})^{T}\right)\right] \\
\mathbf{u} \cdot \nabla C=\nabla \cdot\left(D_{\mathrm{O} 2-\operatorname{air}} \nabla C\right)
\end{gathered}
$$

In order to reduce the computational cost of the numerical solution, the entire length of the channel was divided into three sections and the resulting shorter channel sections were simulated sequentially along the flow direction. The resulting flow profiles at the exit of the first and second sections were mapped as inlet conditions for the following sections. All films were housed in the third section. The array of films was placed $5.00 \mathrm{~mm}$ from the section inlet. For convenience, $x=0$ and $5.00 \mathrm{~mm}$ will refer to the third channel inlet and the location of the first film, respectively in the following text. This technique was verified by comparing two approaches that simulated the entire channel either as a single domain and three separate domains. 
The numerical domain is meshed with tetrahedral mesh elements and boundary layer mesh elements were used on the channel walls and film boundaries to increase accuracy. The maximum mesh element size was 102.0 $\mu \mathrm{m}$, established as a result of a mesh independency study to be presented in Section 3.1.

\subsection{Boundary Conditions and the Numerical Solution Technique}

The magnitude of $\mathrm{O}_{2}$ flux into the GDL-air channel interface $\left(j_{\mathrm{O} 2 \text {,int }}\right)$ is a function of $i$, which was assumed to be uniform over the entire active area and ranged from 0.1 to $1.5 \mathrm{~A} \mathrm{~cm}^{-2}$. With Faraday's law, the magnitude of $\mathrm{O}_{2}$ flux at the interface was calculated to be $j_{\mathrm{O} 2 \text {,int }}=0.444 \times 10^{-2}-6.662 \times 10^{-2} \mathrm{~mol} \mathrm{~m}^{-2} \mathrm{~s}^{-1}$. A uniform velocity profile was imposed at the channel inlet with the corresponding superficial air velocity $\left(u_{\mathrm{m}}\right)$. Table 1 presents the mapping from $i$ to $u_{\mathrm{m}}$ and Pe.

Uniform $\mathrm{O}_{2}$ concentration $\left(3.83 \mathrm{~mol} \mathrm{~m}^{-3}\right.$ ) was imposed at the inlet. Zero gauge pressure was imposed at the outlet. At this boundary, species transport took place only by advection. No-slip boundary condition was imposed at the channel side walls, top wall, and film surfaces. Since the $\mathrm{O}_{2}$ transport through the film is negligible compared to that at the GDL-air channel interface, the $\mathrm{O}_{2}$ flux $\left(j_{\mathrm{O} 2}\right)$ was imposed to be zero on the film boundary. The side top walls of the channel had zero $j_{\mathrm{O} 2}$.

The numerical model was solved with COMSOL Multiphysics ${ }^{\circledR} 4.3$, utilizing the iterative solver, Generalized Minimum Residual Method (GMRES), which utilizes a geometric multigrid scheme. The unknowns of $\mathbf{u}$ and $C$ were represented with second-order shape functions while $p$ was represented with a firstorder one. Automatically scaled error residuals were required to converge to $10^{-6}$.

\subsection{Film Adhesion Analysis}

Fig. 2 shows a typical film viewed from two orthonormal axes: $z$ (top of the channel) and $y$ (side of the channel). The triple-phase contact lines (TPCLs) are shown with solid lines on the top and side channel walls in Figs. $2 a$ and $2 b$, respectively. TPCL on the GDL is shown with a line of dashes and dots in Fig. 2a. The length of the film $\left(L_{\mathrm{f}}\right)$ was assigned to be zero to represent the earlier stages of water emergence from the GDL (not shown in Fig. 2). For curved TPCLs, two angular position variables were defined $\left(\alpha_{y}\right.$ and $\left.\alpha_{z}\right)$ and were measured between the normal to the TPCL and flow directions. As the convention, the angle $\alpha=0$ is directed towards the upstream of the air flow.

The adhesion force of a film $\left(F_{\mathrm{ad}}\right)$ has components from the GDL $\left(F_{\mathrm{ad}, \mathrm{GDL}}\right)$, channel side wall $\left(F_{\text {ad,side }}\right)$ and

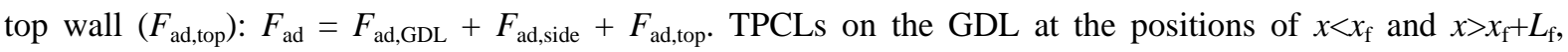
correspond to the footprint of truncated spheres and hence, are the split components of a droplet footprint. The 
GDL component of the adhesion force was calculated through the adhesion force per unit footprint perimeter which is provided by Das et al. [36]. They experimentally obtained this force for aged Sigracet (SGL) 24BA

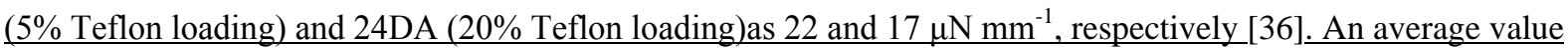
of $20 \mu \mathrm{N} \mathrm{mm}^{-1}$ was used in the adhesion force calculations.

The adhesion force due to the air channel side wall and top wall can be calculated using the contact angle hysteresis obtained for the wall material. The contact angles on the channel walls range from $\theta_{\text {rec }}$ to $\theta_{\text {st }}$ as $\alpha$ varies from 0 to $\pi / 2$. For values of $\pi / 2 \leq \alpha \leq \pi, \theta$ varies from $\theta_{\mathrm{st}}$ to $\theta_{\mathrm{adv}}$. Utilizing Eqs. (15) - (18), contributions to the adhesion force from the aforementioned walls can be calculated at curved TPCLs. Eqs. (16) and (127) assume a linear variation from the advancing to receding contact angle points at the TPCL. For straight TPCLs that are normal to the $x$ axis, the entire line takes either an advancing or a receding contact angle value.

$$
\begin{gathered}
F_{\mathrm{ad}}=\sigma W_{\mathrm{f}} \int_{\alpha=0}^{\pi} \cos \alpha \cos \theta \mathrm{d} \alpha \\
\theta=\theta_{\text {ramp }}\left[\theta_{\mathrm{adv}}-\theta_{\text {rec }}\right]+\theta_{\text {rec }} \\
\theta_{\text {ramp }}=\alpha / \pi \\
\alpha=\left\{\begin{array}{c}
\left(x \leq x_{\mathrm{f}}\right) \rightarrow \cos ^{-1}\left[\left(x_{\mathrm{f}}-x\right) / W_{\mathrm{f}}\right] \\
{\left[x_{\mathrm{f}}<x<\left(x_{\mathrm{f}}+L_{\mathrm{f}}\right)\right] \pi / 2} \\
{\left[x \geq\left(x_{\mathrm{f}}+L_{\mathrm{f}}\right)\right] \rightarrow \cos ^{-1}\left[\left(x_{\mathrm{f}}+L_{\mathrm{f}}-x\right) / W_{\mathrm{f}}\right]}
\end{array}\right.
\end{gathered}
$$

The integral in Eq. (15) needs to be calculated at each curved TPCL as shown in Fig. 2, except the ones on the GDL. The contributions to adhesion force from the side and top walls, and the GDL are presented in Table 2. At the smallest film width, the side walls contribute the most to the adhesion force. The GDL provides the highest contribution for $W_{\mathrm{f}} \geq 0.25 \mathrm{~mm}$. These contributions are independent of the film length.

Table 3 presents numerically calculated drag forces on a film $\left(F_{\mathrm{D}, \mathrm{f}}\right)$ with zero-length $\left(L_{\mathrm{f}}=0\right)$ at variable width $\left(W_{\mathrm{f}}\right)$ and superficial air velocities $\left(u_{\mathrm{m}}\right)$. For a given $W_{\mathrm{f}}, u_{\mathrm{m}}$ was increased incrementally until detachment was achieved. The value of $u_{\mathrm{m}}$ at which detachment was achieved for a given $W_{\mathrm{f}}$ was used as the maximum value for any film length. As films elongate $\left(L_{\mathrm{f}}>0\right)$, the drag has an additional contribution from the shear applied to the side of the film. Non-zero length films were assumed to detach when their respective zero-length analysis predicted the detachment.

Utilizing the aforementioned detachment prediction, each film length had 58 simulated cases as shown in Table 3. As there were 4 film lengths simulated, a total of 232 simulations were performed. For building Sh correlations, combinations of $W_{\mathrm{f}}-u_{\mathrm{m}}$ were selected to match the attachment cases presented for zero film lengths in Table 3. A total of 208 data points were used to build the correlations.Table 4 presents the $W_{\mathrm{f}}-u_{\mathrm{m}}$ combinations that were analyzed for multiple film scenarios. There are 21 cases in this table. A case in Table 4 
was repeated for every combination of 4 film lengths and 3 film spacing values. This led to 252 multiple film simulations.

\section{Results}

\subsection{Mesh and Geometry Independency of Films}

A mesh independency study was conducted for a single, zero-length film with the respective parameters of $W_{\mathrm{f}}$ and $u_{\mathrm{m}}: 0.50 \mathrm{~mm}$ and $10.59 \mathrm{~m} \mathrm{~s}^{-1}$. A zero-length film was preferred as it causes the largest flow disruption and hence, the strongest requirement for a high quality mesh. Comparisons were made between two mesh cases with maximum mesh element sizes of 68.6 and $102.0 \mu \mathrm{m}$. The drag forces on the film $\left(F_{\mathrm{D}, \mathrm{f}}\right)$ showed no significant variance between the two mesh cases. Local Sh profiles were also compared and no detectable difference was found.. Therefore, the mesh with a maximum element size of $102.0 \mu \mathrm{m}$ was used for all film simulations as it was less computationally demanding. In this mesh configuration, the fully developed channel Sh $\left(\mathrm{Sh}_{\mathrm{FD}, \mathrm{ch}}=3.35\right)$ and Pouiselle number $\left(\mathrm{Po}_{\mathrm{FD}, \mathrm{ch}}=15.12\right)$, match with well-established values in the literature as presented earlier [21].

Following the mesh independency verification, the effect of film entrance type on local Sh was investigated. Dimensions of $r_{\mathrm{x}}$ and $r_{\mathrm{y}}$ that were shown in Fig. 1 defines the entrance type which helps to establish a convention for defining the film shape. In one geometrical configuration, referred to as "Sharp Entrance", $r_{x}$ and $r_{y}$ were selected to be equal and are shown in Fig. 1a. Another geometrical configuration, referred to as "Smooth Entrance", represents physical conditions of large air velocities with $r_{x}=2 r_{y}$. In both configurations, $W_{\mathrm{f}}$ is equal to $r_{y}$ which was kept $\mathrm{t}$ at $0.50 \mathrm{~mm}$ with an air velocity of $10.59 \mathrm{~m} \mathrm{~s}^{-1}$. The rationale behind selecting high values of $u_{\mathrm{m}}$ and $W_{\mathrm{f}}$ was obtaining a high dependency of local Sh on the film entrance type.

Fig. 3 shows the effect of entrance types as described in the paragraph above on Sh. At the location where a film reaches its full width, local Sh values reach their respective maxima. After a distance of $W_{\mathrm{f}}$ downstream of the Sh peak, the maximum difference between local Sh values remains within $10 \%$. Hence, the effect of film entrance type on Sh can be neglected in this study. For the convenience of defining the film geometry, "Sharp Entrance" convention was selected to be used for the simulations.

\subsection{Zero-Length Films}


The first set of simulations was performed for zero length films. Figs. $4 \mathrm{a}$ and $4 \mathrm{~b}$ show cases with an absence and presence of Sh overshoot, respectively, the presence of which is dependent on Pe and $W_{\mathrm{f}}^{*}$. In the film wake, a $\mathrm{Sh}$ minimum $\left(\mathrm{Sh}_{\min }\right)$ is observed followed by, in certain cases, a local maximum $\left(\mathrm{Sh}_{\max }\right)$. When within $1 \%$ range, Sh was assumed to converge to $\mathrm{Sh}_{\mathrm{FD}, \mathrm{ch}}$.

The presence of Sh overshoot in the film wake was only seen in the shortest film length $\left(L_{\mathrm{f}}=0\right)$, and at high Pe and $W_{\mathrm{f}}^{*}$ values. The highest $\mathrm{Sh}_{\max }$ was 3.46 at the conditions $\mathrm{Pe}=174.22$ and $W_{\mathrm{f}}^{*}=0.78$. Since this value corresponds only to a $3 \%$ increase above $\mathrm{Sh}_{\mathrm{FD}, \mathrm{ch}}$, the conditions that lead to Sh overshoot were post-processed without reporting $\mathrm{Sh}_{\max }$ values.

Minimum values of Sh that are downstream of a film are always seen at a position $\left(x_{\min }\right)$ in between the film $\left(x_{\mathrm{f}}\right)$ and the downstream end of the film $\left(x_{\mathrm{f}}+W_{\mathrm{f}}\right)$. Since film-affected wake is much longer compared to $W_{\mathrm{f}}, \mathrm{Sh}_{\mathrm{min}}$ can be assumed to be located at the film $\left(x_{\mathrm{f}}\right)$ while generating the Sh profile from the correlations. Tables 5 and 6 respectively show normalized $\mathrm{Sh}_{\min }$ and the distance required to converge to $\mathrm{Sh}_{\mathrm{FD}, \text { ch }}$ downstream of $\mathrm{Sh}_{\min }$. Only a select number of data points are presented in the tables as they were sufficient to show the trends. The correlations to be presented will cover the entire set of data points simulated.

The values in Table 5, which range from 0.46 to 0.92 , decrease with $W_{\mathrm{f}}^{*}$ and increase with Pe. The emboldened values indicate a Sh overshoot in the film wake as shown in Fig. 4b. These cases are the minority since the films detach before the Pe and $W_{\mathrm{f}}^{*}$ can become sufficiently high.

In Table 6, for conditions with no Sh overshoot, values range from 1.51 to $5.33 \mathrm{~mm}$, increase with both Pe and $W_{\mathrm{f}}{ }^{*}$. The film-affected distances are many times larger than the size of the films inducing this effect. For conditions with Sh overshoot (shown with emboldened values), the distance is shortened drastically, as exemplified by the difference between Fig. $4 \mathrm{a}$ and $4 \mathrm{~b}$. The term "convergence" is used superficially to refer to the point where the $\mathrm{Sh}$ profile crosses $\mathrm{Sh}_{\mathrm{FD}, \text { ch }}$ for the first time. This crossing occurs upstream of the overshoot position. The actual convergence occurs downstream of the overshoot. However, downstream of the overshoot is not an area of interest since the overshoot is not strong enough to diverge from $\mathrm{Sh}_{\mathrm{FD}, \mathrm{ch}}$ significantly.

\subsection{Films with a Length Larger than Zero}

Fig. 5 shows a typical Sh profile for films with lengths larger than zero. This profile has characteristic points that are shared by films with zero length: $x_{\max }, x_{\min }$, and $x_{\text {conv }}$. In addition to these shared points, there is another characteristic point specific to films with lengths larger than zero. This point indicates the $\left.\mathrm{Sh}_{(\mathrm{Sh}}\right)$ in the vicinity of film exit $\left(x_{\text {ext }}\right)$ where film width starts tapering off to zero from $W_{\mathrm{f}}$ in the flow direction. 
Sh on the side of a film exponentially decreases in the flow direction as shown in Fig. 3 . If $L_{\mathrm{f}}$ is large enough, the value of $\mathrm{Sh}_{\mathrm{ext}}$ can reach to a fully developed film $\mathrm{Sh}\left(\mathrm{Sh}_{\mathrm{FD}, \mathrm{f}}\right)$. It is important to underline the difference between $\mathrm{Sh}_{\mathrm{FD}, \mathrm{f}}$ and $\mathrm{Sh}_{\mathrm{FD}, \mathrm{ch}}$. The value of $\mathrm{Sh}_{\mathrm{FD}, \mathrm{ch}}$ is singular and specific to the dry channel cross section of $0.70 \mathrm{~mm} \times 0.40 \mathrm{~mm}$. On the contrary, the value of $\mathrm{Sh}_{\mathrm{FD}, \mathrm{f}}$ is plural and varies with the cross section of the channel that is left after the partial occupancy by a film. For the aforementioned reason, $\mathrm{Sh}_{\mathrm{FD}, \mathrm{f}}$ varies with the film width. Table 7 presents $\mathrm{Sh}_{\mathrm{FD}, \mathrm{f}}$ as a function of $W_{\mathrm{f}}^{*}$. Values of $\mathrm{Sh}_{\mathrm{f}, \mathrm{FD}}$ are inversely proportional to $W_{\mathrm{f}}^{*}$.

A film with non-zero length creates a strong variation of local Sh from its entrance to its exit. Comparison between $\mathrm{Sh}_{\max }$ and $\mathrm{Sh}_{\mathrm{ext}}$ can be made using the tables below. $\mathrm{Sh}_{\max }$ is independent of film length and a function of Pe and $W_{\mathrm{f}}{ }^{*}$. Values of $\mathrm{Sh}_{\max }$ are first normalized with the corresponding $\mathrm{Sh}_{\mathrm{FD}, \mathrm{f}}$ and then presented in Table 8. The maximum value of $\mathrm{Sh}_{\mathrm{max}} / \mathrm{Sh}_{\mathrm{FD}, \mathrm{f}}$ was obtained to be 2.25 at the conditions of $\mathrm{Pe}=121.91$ and $W_{\mathrm{f}} *=0.78$.

Table 9 shows $\mathrm{Sh}_{\mathrm{ext}}$ after it is normalized with the corresponding $\mathrm{Sh}_{\mathrm{FD}, \mathrm{f}}$ for $L_{\mathrm{f}}{ }^{*}=1.96\left(L_{\mathrm{f}}=1.00 \mathrm{~mm}\right)$. Other non-tabulated $\mathrm{Sh}_{\mathrm{ext}}$ results, that were obtained from other $L_{\mathrm{f}}^{*}$ simulations, were also used to analyze $\mathrm{Sh}_{\mathrm{ext}}-L_{\mathrm{f}} *$ dependency. $\mathrm{Sh}_{\mathrm{ext}}$ is a function of how much the air flow is developed from the film inlet to exit. Hence, the value is dependent on Pe, $W_{\mathrm{f}}^{*}$, and $L_{\mathrm{f}}^{*}$. Both Pe and $W_{\mathrm{f}}^{*}$ increase $\mathrm{Sh}_{\mathrm{ext}} \mathrm{Sh}_{\mathrm{FD}, \mathrm{f}}$ while $L_{\mathrm{f}}^{*}$ decreases it. The largest deviation of $\mathrm{Sh}_{\mathrm{ext}}$ from $\mathrm{Sh}_{\mathrm{FD}, \mathrm{f}}$ is $15 \%$, which occurs at $L_{\mathrm{f}}^{*}=9.80$.

Values of $\mathrm{Sh}_{\min } / \mathrm{Sh}_{\mathrm{FD}, \mathrm{ch}}$ show the same dependency on Pe and $W_{\mathrm{f}}^{*}$ as observed in zero-length films. Values of $\mathrm{Sh}_{\min } / \mathrm{Sh}_{\mathrm{FD}, \mathrm{ch}}$ either remain the same or decrease with $L_{\mathrm{f}} *$. When the flow is nearly fully developed on the side of a film (low Pe and low $W_{\mathrm{f}}^{*}$ ), $\mathrm{Sh}_{\mathrm{min}} / \mathrm{Sh}_{\mathrm{FD}, \text { ch }}$ show either no difference or an insignificant difference with $L_{\mathrm{f}} *$. For other conditions, the larger the $L_{\mathrm{f}}^{*}$ value is the smaller $\mathrm{Sh}_{\min } / \mathrm{Sh}_{\mathrm{FD}, \mathrm{ch}}$ becomes. The minimum $\mathrm{Sh}_{\min } / \mathrm{Sh}_{\mathrm{FD}, \mathrm{ch}}=$ 0.39 was obtained at conditions of $\mathrm{Pe}=26.16, W_{\mathrm{f}}^{*}=0.98$, and $L_{\mathrm{f}}^{*}=3.92$ and 9.80. Due to this low value, the $\mathrm{Sh}$ convergence length in the film wake has high transport resistance.

Results reveal that Pe, $W_{\mathrm{f}}^{*}$, and $L_{\mathrm{f}}^{*}$ positively affect the convergence length $\left(x_{\text {conv }}-x_{\mathrm{f}}-L_{\mathrm{f}}\right)$. All the tabulated convergence lengths show that films, regardless their lengths, affect a downstream distance much longer than the respective film length. This distance can be as long as $13.48 \mathrm{~mm}$ for a film with $L_{\mathrm{f}}^{*}=9.80$ when Pe and $W_{\mathrm{f}} *$ were 174.22 and 0.59 , respectively.

\subsection{Sh Correlations for Films}

In this section, non-dimensional correlations of Sh are provided for the side of a film that remains exposed to air flow and the film wake. The first step to correlate $\mathrm{Sh}_{\mathrm{eff}}$ is to relate $\mathrm{Sh}_{\mathrm{eff}}$ and $\mathrm{Sh}$ by using Eqs. (6) and (11). The conditional statement in Eq. (6) outputs a non-zero $W_{\text {wet }}$ value when down-the-channel position corresponds 
to a film. The maximum variation between $\mathrm{Sh}_{\mathrm{eff}}$ and $\mathrm{Sh}$ occurs at the largest film width with the relation of $\mathrm{Sh}_{\mathrm{eff}}=\mathrm{Sh} \times 0.69$.

\subsubsection{Correlations of Sh on the Side of a Film}

Eq. (19) provides the correlation for $\mathrm{Sh}_{\mathrm{FD}, \mathrm{f}}$. Local $\mathrm{Sh}$ on the side of a film is expressed with respect to $\mathrm{Sh}_{\mathrm{FD}, \mathrm{f}}$ in Eq. (20). The variation of $\mathrm{Sh} / \mathrm{Sh}_{\mathrm{FD}, \mathrm{f}}$ along the flow length resembles the Graetz problem. This resemblance allows a logarithmic correlation between the non-dimensional distance along the film $\left(x_{\mathrm{f}, n} *\right)$ and the value of $\mathrm{Sh} / \mathrm{Sh}_{\mathrm{FD}, \mathrm{f}}$

$$
\mathrm{Sh}_{\mathrm{FD}, \mathrm{f}}=1.5234 W_{\mathrm{f}}^{* 2}-2.7649 W_{\mathrm{f}}^{*}+3.5643
$$

Eq. (20) utilizes $x_{\mathrm{f}, n}{ }^{*}$ which is defined in Eq. (21). The coefficients $a_{1}$ and $b_{1}$ are expressed in Eq. (22). The use of Eq. (20) within the film region leads to a $\mathrm{Sh} / \mathrm{Sh}_{\mathrm{FD}, \mathrm{f}}$ value that is larger than unity at the film entrance. As $x_{\mathrm{f}, n}{ }^{*}$ grows in the flow direction, there is a value of $x_{\mathrm{f}, n}{ }^{*}$ at which $\mathrm{Sh} / \mathrm{Sh}_{\mathrm{FD}, \mathrm{f}}$ reaches to unity. For any value of $\mathrm{x}_{\mathrm{f}, n} *$ further downstream, Eq. (20) should continue outputting unity. In order to ensure that the logarithmic function does not output any value lower than unity, Eq. (20) is written as a conditional statement.

$$
\frac{\mathrm{Sh}}{\mathrm{Sh}_{\mathrm{FD}, \mathrm{f}}}=\left\{\begin{array}{c}
\left\{\left[a_{1} \log _{10}\left(x_{\mathrm{f}, n}^{*}\right)+b_{1}\right] \leq 1\right\} \rightarrow a_{1} \log _{10}\left(x_{\mathrm{f}, n}^{*}\right)+b_{1} \\
\left\{\left[a_{1} \log _{10}\left(x_{\mathrm{f}, n}^{*}\right)+b_{1}\right]>1\right\} \rightarrow 1
\end{array}\right.
$$

The non-dimensional distance, $x_{\mathrm{f}, n} *$ is a function $n$ in the flow direction and $\Delta x_{\mathrm{f}}$ (in cases of multiple films), and $L_{\mathrm{f}}$. The dimensional distance on the side of a film is non-dimensionalized with $d_{\mathrm{h}}$ and Pe.

$$
\begin{gathered}
x_{\mathrm{f}, n}^{*}=\left[x-x_{\mathrm{f}, 1}-(n-1)\left(\Delta x_{\mathrm{f}}+L_{\mathrm{f}}\right)\right] d_{\mathrm{h}}^{-1} \mathrm{Pe}^{-1} \\
{\left[\begin{array}{l}
a_{1} \\
b_{1}
\end{array}\right]=\left[\begin{array}{ll}
a_{2} & b_{2} \\
a_{3} & b_{3}
\end{array}\right]\left[\begin{array}{c}
\mathrm{Pe} \\
1
\end{array}\right]} \\
{\left[\begin{array}{l}
a_{2} \\
b_{2}
\end{array}\right]=\left[\begin{array}{ll}
-0.0031 & 0.0005 \\
-0.2175 & -0.0528
\end{array}\right]\left[\begin{array}{c}
W_{\mathrm{f}}^{*} \\
1
\end{array}\right]} \\
{\left[\begin{array}{l}
a_{3} \\
b_{3}
\end{array}\right]=\left[\begin{array}{ccc}
0.004 & -0.0072 & 0.0016 \\
0.1187 & -0.2031 & 0.9438
\end{array}\right]\left[\begin{array}{c}
W_{\mathrm{f}}^{* 2} \\
W_{\mathrm{f}}^{*} \\
1
\end{array}\right]}
\end{gathered}
$$

\subsubsection{Correlations of Sh in the Film Wake}

Similarly to the previous section, Sh trends in the film wake resembles the Graetz problem. Local Sh is normalized with $\mathrm{Sh}_{\mathrm{FD}, \mathrm{ch}}$ and then correlated to non-dimensional distance measured from the start of the film end $\left(x_{\mathrm{w}, n} *\right)$. The logarithmic correlation between $\mathrm{Sh} / \mathrm{Sh}_{\mathrm{FD}, \mathrm{ch}}$ and $x_{\mathrm{w}, n} *$ is presented in Eq. (25). The definition of $x_{\mathrm{w}, n} *$ is provided in Eq. (26). 


$$
\begin{gathered}
\frac{\mathrm{Sh}}{\mathrm{Sh}_{\mathrm{FD}, \mathrm{ch}}}=\left\{\begin{array}{c}
\left\{\left[a_{1} \log _{10}\left(x_{\mathrm{w}, n}^{*}\right)+b_{1}\right] \leq 1\right\} \rightarrow a_{1} \log _{10}\left(x_{\mathrm{W}, n}^{*}\right)+b_{1} \\
\left\{\left[a_{1} \log _{10}\left(x_{\mathrm{w}, n}^{*}\right)+b_{1}\right]>1\right\} \rightarrow 1
\end{array}\right. \\
x_{\mathrm{w}, n}^{*}=\left[x-x_{\mathrm{f}, 1}-n L_{\mathrm{f}}-(n-1) \Delta x_{\mathrm{f}}\right] d_{\mathrm{h}}^{-1} \mathrm{Pe}^{-1}
\end{gathered}
$$

The correlations for $a_{2}, a_{3}, b_{2}$, and $b_{3}$ are available for two different ranges of Pe, namely Pe $\leq 69.75$ and Pe $\geq 69.75$. The aforementioned correlations for $\mathrm{Pe} \leq 69.75$ are presented in Eqs. (27) - (31).

$$
\begin{aligned}
& {\left[\begin{array}{l}
a_{2} \\
b_{2}
\end{array}\right]=\left[\begin{array}{cc}
-0.0096 a_{4} & 0.0009 b_{4} \\
0.8926 a_{5} & -0.0393 b_{5}
\end{array}\right]\left[\begin{array}{c}
W_{\mathrm{f}}^{*} \\
1
\end{array}\right]} \\
& {\left[\begin{array}{l}
a_{4} \\
b_{4} \\
a_{5} \\
b_{5}
\end{array}\right]=\left[\begin{array}{c}
0.7083+(5.955-0.7083) \exp \left(-1.13 L_{\mathrm{f}}^{*}\right) \\
0.8889+(81.89-0.8889) \exp \left(-1.682 L_{\mathrm{f}}^{*}\right) \\
0.865+(6.033-0.865) \exp \left(-1.345 L_{\mathrm{f}}^{*}\right) \\
-1.677+(66.05+1.677) \exp \left(-1.37 L_{\mathrm{f}}^{*}\right)
\end{array}\right]} \\
& {\left[\begin{array}{l}
a_{3} \\
b_{3}
\end{array}\right]=\left[\begin{array}{ccc}
0.0163 a_{6} & -0.0282 b_{6} & 0.0071 c_{6} \\
-0.9007 a_{7} & 1.7209 b_{7} & 0.732 c_{7}
\end{array}\right]\left[\begin{array}{c}
W_{\mathrm{f}}^{* 2} \\
W_{\mathrm{f}}^{*} \\
1
\end{array}\right]} \\
& {\left[\begin{array}{l}
a_{6} \\
b_{6} \\
c_{6}
\end{array}\right]=\left[\begin{array}{lll}
0.0274 & -0.338 & 1.0138 \\
0.0216 & -0.2722 & 1.0193 \\
0.0222 & -0.2837 & 1.0259
\end{array}\right]\left[\begin{array}{c}
L_{\mathrm{f}}^{* 2} \\
L_{\mathrm{f}}^{*} \\
1
\end{array}\right]} \\
& {\left[\begin{array}{l}
a_{7} \\
b_{7} \\
c_{7}
\end{array}\right]=\left[\begin{array}{ccc}
0.0145 & -0.1445 & 1.0089 \\
0.0103 & -0.1138 & 1.0288 \\
-0.0084 & 0.0994 & 0.9771
\end{array}\right]\left[\begin{array}{c}
L_{\mathrm{f}}^{* 2} \\
L_{\mathrm{f}}^{*} \\
1
\end{array}\right]} \\
& {\left[\begin{array}{l}
a_{2} \\
b_{2}
\end{array}\right]=\left[\begin{array}{ccc}
0.0099 a_{4} & -0.0086 b_{4} & 0.0014 c_{4} \\
-0.701 a_{5} & 1.1288 b_{5} & -0.211 c_{5}
\end{array}\right]\left[\begin{array}{c}
W_{\mathrm{f}}^{* 2} \\
W_{\mathrm{f}}^{*} \\
1
\end{array}\right]} \\
& {\left[\begin{array}{l}
a_{4} \\
b_{4} \\
c_{4}
\end{array}\right]=\left[\begin{array}{ccc}
0.0523 & -0.7199 & 1.9882 \\
0.056 & -0.762 & 2.2791 \\
0.0805 & -1.0929 & 3.1905
\end{array}\right]\left[\begin{array}{c}
L_{\mathrm{f}}^{* 2} \\
L_{\mathrm{f}}^{*} \\
1
\end{array}\right]} \\
& {\left[\begin{array}{l}
a_{5} \\
b_{5} \\
c_{5}
\end{array}\right]=\left[\begin{array}{lll}
0.0547 & -0.7215 & 2.3618 \\
0.0243 & -0.3001 & 1.5204 \\
0.0262 & -0.3078 & 0.985
\end{array}\right]\left[\begin{array}{c}
L_{\mathrm{f}}^{* 2} \\
L_{\mathrm{f}}^{*} \\
1
\end{array}\right]} \\
& {\left[\begin{array}{l}
a_{3} \\
b_{3}
\end{array}\right]=\left[\begin{array}{ccc}
0.0241 a_{6} & -0.0165 b_{6} & 0.0023 c_{6} \\
-1.6684 a_{7} & 1.6517 b_{7} & 0.7465 c_{7}
\end{array}\right]\left[\begin{array}{c}
W_{\mathrm{f}}^{* 2} \\
W_{\mathrm{f}}^{*} \\
1
\end{array}\right]} \\
& {\left[\begin{array}{l}
a_{6} \\
b_{6} \\
c_{6}
\end{array}\right]=\left[\begin{array}{lll}
0.0022 & -0.0471 & 0.3451 \\
0.0058 & -0.0835 & 0.4747 \\
0.0302 & -0.3991 & 1.3623
\end{array}\right]\left[\begin{array}{c}
L_{\mathrm{f}}^{* 2} \\
L_{\mathrm{f}}^{*} \\
1
\end{array}\right]} \\
& {\left[\begin{array}{l}
a_{7} \\
b_{7} \\
c_{7}
\end{array}\right]=\left[\begin{array}{ccc}
-0.0169 & 0.2154 & -0.1135 \\
-0.0175 & 0.2492 & -0.207 \\
0.0022 & -0.0484 & 1.5556
\end{array}\right]\left[\begin{array}{c}
L_{\mathrm{f}}^{* 2} \\
L_{\mathrm{f}}^{*} \\
1
\end{array}\right]}
\end{aligned}
$$

\subsubsection{Accuracy of Single-Film Sh Correlations}


Fig. 6 presents a representative comparison between the numerically generated Sh and correlation-predicted $\mathrm{Sh}\left(\mathrm{Sh}_{\mathrm{cor}}\right)$ at the film wake. This film has the following configuration: $\mathrm{Pe}=26.16, W_{\mathrm{f}}^{*}=0.39$, and $L_{\mathrm{f}}^{*}=9.80$. Fig. 6a shows the superposition of $\mathrm{Sh}$ and $\mathrm{Sh}_{\mathrm{cor}}$ plotted against the logarithm of non-dimensionalized distance in the film wake $\left(x_{\mathrm{w}}{ }^{*}\right)$ as defined in Eq. (26). As Fig. 6a depicts, there is a very good agreement between the numerical data and the prediction. A quantification of the prediction accuracy is presented in Fig. $6 \mathrm{~b}$. This figure presents the ratio of $\mathrm{Sh}_{\text {cor }} / \mathrm{Sh}$. It can be noted that the maximum error for the prediction is $10 \%$.

\subsubsection{Applicability of Single-Film Sh Correlations to Multiple Films and Different Air Properties}

The correlations presented in the previous section were built using the single-film simulation results. The applicability of these correlations to multiple-film scenarios is important for simplified PEMFC performance models to account for realistic conditions. For the analysis of this applicability, typical multiple-film scenarios will be presented initially, followed by the characterization of single-film correlations for their applicability to multiple-film scenarios.

Multiple-film Sh results can resemble those of single-films as $\Delta x_{\mathrm{f}}$ becomes large enough or the set of Pe$W_{\mathrm{f}}^{*}$ values becomes small enough. In multiple-film simulations, $\Delta x_{\mathrm{f}}^{*}$ took values of $1.96,3.92$, and 9.80 (corresponding to dimensional values of $\Delta x_{\mathrm{f}}=1.00,2.00$, and $5.00 \mathrm{~mm}$ ).

Single-film Sh correlations were characterized for their applicability to multiple-film predictions. Fig. 7 presents the local ratio of $\mathrm{Sh}_{\text {cor }}$ to $\mathrm{Sh}$. This ratio represents the prediction accuracy and was plotted for 3 consecutive films. The plot includes 21 conditions as a result of different permutations of Pe and $W_{\mathrm{f}}{ }^{*}$ as shown in Table 4. The results indicate that the largest error values can be seen in the beginning of a film and at the film wake. However, all error values are within $20 \%$.

All multiple-film simulation results were used to characterize the accuracy of the correlations built with single-film results. Similar results were obtained to those shown in Fig. 7. These results were first transformed into absolute error percentage values $\left(100 \times\left|1-\mathrm{Sh}_{\text {cor }} / \mathrm{Sh}\right|\right)$ and then averaged through the flow direction for all multiple-film simulations. The resulting value is called mean absolute percentage error (MAPE) as formally defined in Eq. (38). Each down the channel location is referred to with the variable, $x_{\mathrm{t}}$ in the discrete numerical solution. For an entire number of data points, $k$; the data is averaged.

$$
\text { MAPE }=100 \frac{1}{k} \sum_{t=1}^{k}\left|\frac{\operatorname{Sh}_{\text {cor }}\left(x_{t}\right)-\mathrm{Sh}_{\text {num }}\left(x_{t}\right)}{\operatorname{Sh}_{\text {num }}\left(x_{t}\right)}\right|
$$

The total number of cases is 252 . These cases can be categorized into two groups based on Pe. For the range of $\mathrm{Pe} \leq 52.32$, there are 192 cases. MAPE for these cases is $9 \%$. Among the data points of error, $83 \%$ and $5 \%$ of 
them are in between $0-10 \%$ and 10-20\%, respectively. As a more challenging range of Pe, $\mathrm{Pe}>52.32$ covers 60 cases. In this range, MAPE is $9 \%$ as in the lower range of Pe. However, distribution of error differs by $80 \%$ and $8 \%$ of the data having an error range of $0-10 \%$ and $10-20 \%$, respectively. Under the light of the aforementioned error characterization, the single-film based correlations can be applied to multiple-film cases with accuracy.

Although developed by using results obtained at $80{ }^{\circ} \mathrm{C}$ and $100 \%$ relative humidity, the applicability of the correlations was tested and found to be accurate down to $20^{\circ} \mathrm{C}$ and $0 \%$ relative humidity. The effect of Sc on $\mathrm{Sh}$ at constant values of $\mathrm{Pe}=121.62, W_{\mathrm{f}}^{*}=0.79$, and $L_{\mathrm{f}}^{*}=9.82$ was numerically simulated. Since the effect of $\Delta x_{\mathrm{f}}$ can be neglected based on the results above, the effect of Sc was tested for a single film that results strong flow disruptions. Values of Sc for fully humidified air at temperatures of 20 and $80{ }^{\circ} \mathrm{C}$ are 0.753 and 0.632 , respectively. Sc increases negligibly at temperatures lower than $20{ }^{\circ} \mathrm{C}$ since there is already a $2 \%$ increase from 40 to $20{ }^{\circ} \mathrm{C}$. Hence, the lowest temperature to test the applicability of the correlations was selected to be $20{ }^{\circ} \mathrm{C}$. Comparison of local $\mathrm{Sh}$ at 20 and $80{ }^{\circ} \mathrm{C}$ resulted in a maximum discrepancy of $3 \%$. Variation of relative humidity from 0 to $100 \%$ has a negligible effect on Sc. The mixture of fully humidified air at $20{ }^{\circ} \mathrm{C}$ has a vapor molar fraction of 0.02 . The subtraction of this marginal component to obtain dry air does not lead to a significant difference in Sc. Therefore, the reported simulation result for the effect of Sc is also applicable to dry air at $20^{\circ} \mathrm{C}$.

\subsubsection{Application Example for the Sh Correlations}

The correlations of $\mathrm{Sh}_{\text {eff }}$ provided in this study can be applied to air channels with a characterized film distribution and air velocity. This section utilizes an image from an ex-situ visualization setup that was described in detail by Banerjee and Kandlikar [10]. This setup creates the two-phase flow conditions in a flow field with parallel channels by injecting liquid water through a GDL and into channels. Fig. 8a shows a film with zero length and $0.40 \mathrm{~mm}$ width. This image was taken at $0.4 \mathrm{~A} \mathrm{~cm}^{-2}$ current density, $23{ }^{\circ} \mathrm{C}$ and $0 \%$ relative humidity. These conditions correspond to a Pe of 48.

Fig. 8 b shows $\mathrm{Sh}_{\text {eff }}$ profiles that were obtained for the visualized film through a numerical simulation and correlations. The length that the film covers in the flow direction is shown on the $x$ axis. Since the films have zero length, the flow conditions are the most difficult to predict on the side of the films. On regions that are not covered by the film, the error percentages are below 10\%. This presented approach can be applied to simplified PEMFC performance models to predict the performance loss more accurately. 


\subsubsection{Estimation of the Effect of the Sh Variations on Cell Performance}

Variations of $\mathrm{Sh}_{\text {eff }}$ in air channel due to the presence of films lead to changes in local performance in a fuel cell. The change in performance can be expressed with a change in voltage for a given $i$. An estimation of the voltage change is made by first calculating the $\mathrm{O}_{2}$ concentration at the GDL-air channel interface $\left(C_{\text {int }}\right)$ with films. For this calculation, the outlet of the air channel is chosen as the reduced $\mathrm{O}_{2}$ concentration in this region intensifies the effect of films on transport losses. Use of $\mathrm{Sh}_{\text {eff }}$ provides the loss of $\mathrm{O}_{2}$ concentration from the channel mean value $\left(C_{\mathrm{m}}\right)$ to $C_{\mathrm{int}}$. An additional reduction is applied to find the concentration at the cathode catalyst layer (CL), $C_{\mathrm{CL}}$. The $\mathrm{O}_{2}$ concentration loss from $C_{\mathrm{int}}$ to $C_{\mathrm{CL}}$ is due to the transport resistance of the GDL. For a dry GDL, the $\mathrm{O}_{2}$ diffusivity can be assumed to be $D_{\mathrm{O} 2 \text {-GDL }}=D_{\mathrm{O} 2 \text {-air }} / 1.5$ [32]. Lastly, the effect of changes in $C_{\mathrm{CL}}$ on the cell voltage ( $V$ ) for a given $i$ was calculated. The change in cell voltage from condition 1 to $2\left(\Delta V_{1-2}\right)$ can be expressed with the following equation:

$$
\Delta V_{1-2}=\frac{R_{\mathrm{u}} T}{F_{\mathrm{c}}} \ln \left[\frac{C_{2}}{C_{1}}\right]
$$

As a baseline reference, the value of $\mathrm{Sh}_{\mathrm{FD}, \mathrm{ch}}=3.349$ causes a voltage loss of $9.0 \mathrm{mV}$ at $i=1.5 \mathrm{~A} \mathrm{~cm}{ }^{-2}$ relative to the condition of no interfacial transport resistance $\left(C_{\mathrm{int}} \rightarrow C_{\mathrm{m}}\right)$. A film with the configuration of $W_{\mathrm{f}}^{*}=$ $0.98\left(W_{\mathrm{f}}=0.50 \mathrm{~mm}\right)$ and $L_{\mathrm{f}}^{*}=9.80\left(L_{\mathrm{f}}=5.00 \mathrm{~mm}\right)$ was selected along with the superficial air velocity corresponding to $\mathrm{Pe}=69.75$. The resulting critical points in the flow direction are $\mathrm{Sh}_{\max }=2.19 \times \mathrm{Sh}_{\mathrm{FD}, \mathrm{f}}=$ $2.19 \times 2.32=5.08, \mathrm{Sh}_{\mathrm{ext}}=1.11 \times \mathrm{Sh}_{\mathrm{FD}, \mathrm{f}}=1.11 \times 2.32=2.58, \mathrm{Sh}_{\min }=0.40 \times \mathrm{Sh}_{\mathrm{FD}, \mathrm{ch}}=0.40 \times 3.35=1.34$. Effective Sh is calculated as: $\mathrm{Sh}_{\text {max,eff }}=\mathrm{Sh}_{\max } \times 0.61=3.10$ and $\mathrm{Sh}_{\mathrm{ext}, \mathrm{eff}}=\mathrm{Sh}_{\mathrm{ext}} \times 0.61=1.57$. At the aforementioned $i$, the additional voltage drops at the positions $x_{\max }, x_{\mathrm{ext}}$, and $x_{\min }$ are 1,15 , and $22 \mathrm{mV}$, respectively. These values show that there is a significant voltage drop within the $5.00 \mathrm{~mm}$ long film. Moreover, the voltage drop at the immediate wake of the film lasts approximately $8.31 \mathrm{~mm}$. Hence, the effect of the voltage drop $22 \mathrm{mV}$ lasts more than the film length itself.

A comparison can be made between the impact of interfacial blockage by films and variations of Sh on the side of films. In a scenario of $W_{\mathrm{f}}=0.50 \mathrm{~mm}$ and $i=1.5 \mathrm{~A} \mathrm{~cm}^{-2}$, which is the largest film width in this study, the available interfacial width is $0.61 W_{\text {ch. }}$ A sufficiently long film has a $\mathrm{Sh}_{\mathrm{FD}, \mathrm{f}}$ of 2.32 which is equivalent to $0.69 \mathrm{Sh}_{\mathrm{FD}, \mathrm{ch}}$. If $\mathrm{Sh}$ is assumed to be $\mathrm{Sh}_{\mathrm{FD}, \mathrm{ch}}$ on the side of a film and only the interfacial blockage is considered, $\mathrm{Sh}_{\mathrm{eff}}$ of $0.61 \mathrm{Sh}_{\mathrm{ch}, \mathrm{FD}}$ leads to a voltage drop $8 \mathrm{mV}$. If the interfacial blockage is neglected and only the variation of $\mathrm{Sh}$ is considered, $\mathrm{Sh}_{\mathrm{eff}}$ of $0.69 \mathrm{Sh}_{\mathrm{FD}, \mathrm{ch}}$ leads to a voltage drop of $5 \mathrm{mV}$. Due to the logarithmic dependence of 
voltage loss on the transport resistance, the combination of the aforementioned resistances is significantly detrimental. A $\mathrm{Sh}_{\mathrm{eff}}$ of $0.61 \mathrm{Sh}_{\mathrm{FD}, \mathrm{f}}=0.61 \times 0.69 \mathrm{Sh}_{\mathrm{FD}, \mathrm{ch}}=0.42 \mathrm{Sh}_{\mathrm{FD}, \mathrm{ch}}$ leads to a voltage loss of $20 \mathrm{mV}$.

\section{Conclusions}

This study numerically investigated the $\mathrm{O}_{2}$ transport resistance at the GDL-air channel interface in PEM fuel cells. The resistance is expressed in terms of Sherwood number (Sh). The particular focus of this work was to characterize Sh under film flow conditions which are the most prevalent in an air channel. The effect of single and multiple films on Sh was expressed through correlations that are dependent on non-dimensional film width, length, and spacing, and Péclet number. These correlations can be used in simplified PEMFC performance models to better predict $\mathrm{O}_{2}$ transport losses. Based on the results of this study, the following conclusions can be made:

- There are two fully developed Sh values: one in the channel with the absence of films $\left(\mathrm{Sh}_{\mathrm{FD}, \mathrm{ch}}\right)$ and another on the side of a film that is sufficiently long $\left(\mathrm{Sh}_{\mathrm{FD}, \mathrm{f}}\right) . \mathrm{Sh}_{\mathrm{FD}, \mathrm{ch}}$ remains constant at 3.35. However, $\mathrm{Sh}_{\mathrm{FD}, \mathrm{f}}$ varies between $2.32-2.71$ with the film width.

- Films reduce the area of GDL-air channel interface for $\mathrm{O}_{2}$ transport. This reduction has been accounted for by introducing the effective $\mathrm{Sh}\left(\mathrm{Sh}_{\mathrm{eff}}\right)$. It is equivalent to local $\mathrm{Sh}$ value that is reduced proportionally to the interfacial water coverage.

- In the immediate wake of a film, there is a minimum observed in $\mathrm{Sh}\left(\mathrm{Sh}_{\min }\right)$ which can be as low as $0.39 \mathrm{Sh}_{\mathrm{FD}, \mathrm{ch}}$.

- In the wake of $\mathrm{Sh}_{\min }$, there is a convergence trend of $\mathrm{Sh}$ from $\mathrm{Sh}_{\text {min }}$ to $\mathrm{Sh}_{\mathrm{FD}, \mathrm{ch}}$. This convergence extends over a length similar to the film length. The maximum length was $13.48 \mathrm{~mm}$.

- It was found that Sh on the side of a film varies significantly throughout the film length. The maximum $\mathrm{Sh}\left(\mathrm{Sh}_{\max }\right)$ is found at the entrance of the film and can be as high as $2.25 \mathrm{Sh}_{\mathrm{FD}, \mathrm{f}}$. If the film is long enough for a given $\mathrm{Pe}$, Sh at the exit is $\mathrm{Sh}_{\mathrm{FD}, \mathrm{f}}$.

- Correlations were developed to predict the local Sh profile for the side of a film and its wake. These correlations can be applied multiple-films. The correlations were tested against 252 multiple-film configurations. Mean absolute percentage error for Sh prediction was $9 \%$.

- The maximum interfacial channel width blockage (39\%) and Sh reduction on the side of a film (31\%) lead to a voltage loss of 8 and $5 \mathrm{mV}$, respectively at a current density of $1.5 \mathrm{~A} \mathrm{~cm}^{-2}$. The combined transport resistance due to the aforementioned components is a voltage reduction of $20 \mathrm{mV}$. Hence, Sh 
number correlations in this study should be incorporated into simplified PEMFC models along with interfacial blockage by films.

\section{Acknowledgements}

This work was conducted in the Thermal Analysis, Microfluidics, and Fuel Cell Laboratory in the Mechanical Engineering Department at Rochester Institute of Technology. Support for this project was provided by the U.S. Department of Energy under award number: DE-EE0000470.

\section{REFERENCES}

[1] A. Casalegno, F. Bresciani, G. Groppi, R. Marchesi, Flooding of the diffusion layer in a polymer electrolyte fuel cell: Experimental and modelling analysis, J. Power Sources. 196 (2011) 10632-10639. doi:10.1016/j.jpowsour.2011.08.094.

[2] S. Basu, C.-Y. Wang, K.S. Chen, Phase Change in a Polymer Electrolyte Fuel Cell, J. Electrochem. Soc. 156 (2009) B748. doi:10.1149/1.3115470.

[3] H. Ju, G. Luo, C.-Y. Wang, Probing Liquid Water Saturation in Diffusion Media of Polymer Electrolyte Fuel Cells, J. Electrochem. Soc. 154 (2007) B218. doi:10.1149/1.2401034.

[4] U. Pasaogullari, C.Y. Wang, Two-phase modeling and flooding prediction of polymer electrolyte fuel cells, J. Electrochem. Soc. 152 (2005) A380-A390. doi:10.1149/1.1850339.

[5] J.P. Owejan, J.J. Gagliardo, R.C. Reid, T.A. Trabold, Proton transport resistance correlated to liquid water content of gas diffusion layers, J. Power Sources. 209 (2012) 147-151. doi:10.1016/j.jpowsour.2012.02.087.

[6] J. Eller, T. Rosén, F. Marone, M. Stampanoni, A. Wokaun, F.N. Büchi, Progress in in situ X-ray tomographic microscopy of liquid water in gas diffusion layers of PEFC, J. Electrochem. Soc. 158 (2011) B963-B970.

[7] G.S. Hwang, A.Z. Weber, Effective-Diffusivity Measurement of Partially-Saturated Fuel-Cell GasDiffusion Layers, J. Electrochem. Soc. 159 (2012) F683-F692. doi:10.1149/2.024211jes.

[8] D.R. Baker, C. Wieser, K.C. Neyerlin, M.W. Murphy, The Use of Limiting Current to Determine Transport Resistance in PEM Fuel Cells, in: ECS, 2006: pp. 989-999. doi:10.1149/1.2356218.

[9] D. Lee, J. Bae, Visualization of flooding in a single cell and stacks by using a newly-designed transparent PEMFC, Int. J. Hydrog. Energy. 37 (2012) 422-435. doi:10.1016/j.ijhydene.2011.09.073.

[10] R. Banerjee, S.G. Kandlikar, Liquid water quantification in the cathode side gas channels of a proton exchange membrane fuel cell through two-phase flow visualization, J. Power Sources. 247 (2014) 9-19. doi:10.1016/j.jpowsour.2013.08.016.

[11] J.M. Sergi, S.G. Kandlikar, Quantification and characterization of water coverage in PEMFC gas channels using simultaneous anode and cathode visualization and image processing, Int. J. Hydrog. Energy. 36 (2011) 12381-12392. doi:10.1016/j.ijhydene.2011.06.092.

[12] D. Lorenzini-Gutierrez, S.G. Kandlikar, A. Hernandez-Guerrero, F. Elizalde-Blancas, Residence time of water film and slug flow features in fuel cell gas channels and their effect on instantaneous area coverage ratio, J. Power Sources. 279 (2015) 567-580. doi:10.1016/j.jpowsour.2015.01.041.

[13] X. Zhu, P.C. Sui, N. Djilali, Q. Liao, Dynamics of Emerging Water Droplet Subjected to Sidewall with Different Wettabilities in a Fuel Cell Cathode Channel, Fuel Cells. 11 (2011) 404-412. doi:10.1002/fuce.201100009.

[14] U. Pasaogullari, C.Y. Wang, Liquid Water Transport in Gas Diffusion Layer of Polymer Electrolyte Fuel Cells, J. Electrochem. Soc. 151 (2004) A399-A406. doi:10.1149/1.1646148.

[15] U. Pasaogullari, C.-Y. Wang, K.S. Chen, Two-Phase Transport in Polymer Electrolyte Fuel Cells with Bilayer Cathode Gas Diffusion Media, J. Electrochem. Soc. 152 (2005) A1574. doi:10.1149/1.1938067.

[16] K. Tüber, D. Pócza, C. Hebling, Visualization of water buildup in the cathode of a transparent PEM fuel cell, J. Power Sources. 124 (2003) 403-414. doi:10.1016/S0378-7753(03)00797-3.

[17] W. Gu, D.R. Baker, Y. Liu, H.A. Gast, Proton exchange membrane fuel cell (PEMFC) down-the-channel performance model, in: W. Vielstich, H. Yokokawa, H.A. Gasteiger (Eds.), Handb. Fuel Cells Fundam. Technol. Appl., John Wiley \& Sons, 2009: pp. 631-657. 
[18] H. Liu, P. Li, K. Wang, Optimization of PEM fuel cell flow channel dimensions-Mathematic modeling analysis and experimental verification, Int. J. Hydrog. Energy. 38 (2013) 9835-9846. doi:10.1016/j.ijhydene.2013.05.159.

[19] H. Wu, X. Li, P. Berg, Numerical analysis of dynamic processes in fully humidified PEM fuel cells, Int. J. Hydrog. Energy. 32 (2007) 2022-2031. doi:10.1016/j.ijhydene.2006.09.046.

[20] M. Koz, S.G. Kandlikar, Interfacial oxygen transport resistance in a proton exchange membrane fuel cell air channel with an array of water droplets, Int. J. Heat Mass Transf. 80 (2015) 180-191. doi:10.1016/j.ijheatmasstransfer.2014.08.079.

[21] M. Koz, S.G. Kandlikar, Numerical investigation of interfacial transport resistance due to water droplets in proton exchange membrane fuel cell air channels, J. Power Sources. 243 (2013) 946-957. doi:10.1016/j.jpowsour.2013.06.075.

[22] S.-K. Lee, K. Ito, Cross-Sectional Visualization and Analysis of Droplet Behavior in Gas Flow Channel in PEFC, J. Electrochem. Soc. 161 (2014) F58-F66.

[23] M.J. Cheah, I.G. Kevrekidis, J.B. Benziger, Water Slug Formation and Motion in Gas Flow Channels: The Effects of Geometry, Surface Wettability, And Gravity, Langmuir. 29 (2013) 9918-9934. doi:10.1021/la4011967.

[24] P. Gopalan, S.G. Kandlikar, Effect of channel materials and trapezoidal corner angles on emerging droplet behavior in Proton Exchange Membrane Fuel Cell gas channels, J. Power Sources. 248 (2014) 230-238. doi:10.1016/j.jpowsour.2013.09.070.

[25] J.P. Owejan, J.J. Gagliardo, J.M. Sergi, S.G. Kandlikar, T.A. Trabold, Water management studies in PEM fuel cells, Part I: Fuel cell design and in situ water distributions, Int. J. Hydrog. Energy. 34 (2009) 34363444. doi:10.1016/j.ijhydene.2008.12.100.

[26] C.E. Colosqui, M.J. Cheah, I.G. Kevrekidis, J.B. Benziger, Droplet and slug formation in polymer electrolyte membrane fuel cell flow channels: The role of interfacial forces, J. Power Sources. 196 (2011) 10057-10068. doi:10.1016/j.jpowsour.2011.08.084.

[27] M.M. Shah, S.G. Kandlikar, Water emergence from the land region and water-sidewall interactions in Proton Exchange Membrane Fuel Cell gas channels with microgrooves, J. Power Sources. 297 (2015) 127-139. doi:10.1016/j.jpowsour.2015.07.095.

[28] T. Hellstern, E. Gauthier, M.J. Cheah, J.B. Benziger, The role of the gas diffusion layer on slug formation in gas flow channels of fuel cells, Int. J. Hydrog. Energy. 38 (2013) 15414-15427. doi:10.1016/j.ijhydene.2013.09.073.

[29] Frank P. Incropera, David P. DeWitt, Fundamentals of Heat and Mass Transfer, 4th ed., John Wiley \& Sons, Inc., USA, 1996.

[30] P.T. Tsilingiris, Thermophysical and transport properties of humid air at temperature range between 0 and $100^{\circ} \mathrm{C}$, Energy Convers. Manag. 49 (2008) 1098-1110. doi:10.1016/j.enconman.2007.09.015.

[31] C.R. Wilke, Diffusional properties of multicomponent gases, Chem Eng Prog. 46 (1950) 95-104.

[32] M.M. Mench, Fuel cell engines, John Wiley \& Sons, 2008.

[33] E.N. Fuller, P.D. Schettler, J.C. Giddings, New method for prediction of binary gas-phase diffusion coefficients, Ind. Eng. Chem. 58 (1966) 18-27.

[34] M. Koz, S.G. Kandlikar, The Effect of Injection and Suction on the Interfacial Mass Transport Resistance in a Proton Exchange Membrane Fuel Cell Air Channel, in: ASME, Chicago, Illinois, USA, 2014.

[35] P. Gopalan, S.G. Kandlikar, Effect of Channel Material on Water Droplet Dynamics in a PEMFC Gas Channel, J. Electrochem. Soc. 160 (2013) F487-F495. doi:10.1149/2.030306jes.

[36] P.K. Das, A. Grippin, A. Kwong, A.Z. Weber, Liquid-Water-Droplet Adhesion-Force Measurements on Fresh and Aged Fuel-Cell Gas-Diffusion Layers, J. Electrochem. Soc. 159 (2012) B489-B496. doi:10.1149/2.052205jes.

[37] P.J. Pritchard, Fox and McDonald's Introduction to Fluid Mechanics, 8th Edition, 8 edition, John Wiley \& Sons, Inc., 2010.

[38] R. Krishna, J.A. Wesselingh, The Maxwell-Stefan approach to mass transfer, Chem. Eng. Sci. 52 (1997) 861-911. doi:10.1016/S0009-2509(96)00458-7. 


\section{List of Tables}

Table 1: Mapping from current density $(i)$ to superficial air velocity $\left(u_{\mathrm{m}}\right)$ and Péclet number (Pe) for fully humidified air at $80^{\circ} \mathrm{C}$.

Table 2: The net adhesion force on a film $\left(F_{\mathrm{ad}}\right)[\mu \mathrm{N}]$ with its components: GDL $\left(F_{\mathrm{GDL}}\right)$, channel side wall $\left(F_{\text {side }}\right)$ and top wall $\left(F_{\text {top }}\right)$.

Table 3: Drag force $F_{\mathrm{D}, \mathrm{f}}[\mu \mathrm{N}]$ on a film with a length $L_{\mathrm{f}}=0$ at variable film width $\left(W_{\mathrm{f}}\right)$ and superficial air velocity $\left(u_{\mathrm{m}}\right)$.

Table 4: Combinations of film width $\left(W_{\mathrm{f}}\right)$ and superficial air velocity $\left(u_{\mathrm{m}}\right)$ that were simulated for each permutation of film length $\left(L_{\mathrm{f}}\right)$ and uniform spacing $\left(\Delta x_{\mathrm{f}}\right)$.

Table 5: Minimum $\mathrm{Sh}\left(\mathrm{Sh}_{\mathrm{min}}\right)$ in the zero-length film wake normalized with fully developed channel $\mathrm{Sh}$ $\left(\mathrm{Sh}_{\mathrm{FD}, \mathrm{ch}}\right), \mathrm{Sh}_{\mathrm{min}} / \mathrm{Sh}_{\mathrm{FD}, \mathrm{ch}}$, as a function of Péclet number $(\mathrm{Pe})$ and non-dimensional film width $\left(W_{\mathrm{f}}{ }^{*}\right)$. (Emboldened values indicate cases with Sh overshoot. Empty cells indicate conditions in which films detach.)

Table 6: The distance of Sh convergence point with respect to minimum Sh position $\left(x_{\mathrm{conv}}-x_{\min }\right)[\mathrm{mm}]$ in the zero-length film wake. (Empty cells indicate a condition in which films detach. Emboldened values indicate conditions with Sh overshoot in the film wake.)

Table 7: Fully developed film $\mathrm{Sh}$ in a sufficiently long film $\left(\mathrm{Sh}_{\mathrm{FD}, \mathrm{f}}\right)$ with a variable non-dimensional film width $\left(W_{\mathrm{f}}^{*}\right)$.

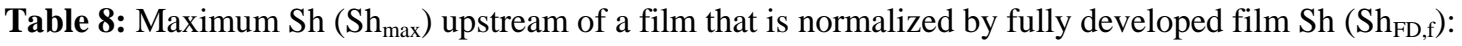
$\mathrm{Sh}_{\max } / \mathrm{Sh}_{\mathrm{FD}, \mathrm{f}}$

Table 9: Film-exit $\mathrm{Sh}\left(\mathrm{Sh}_{\mathrm{ext}}\right)$ normalized with the corresponding fully developed film $\mathrm{Sh}\left(\mathrm{Sh}_{\mathrm{FD}, \mathrm{f}}\right): \mathrm{Sh}_{\mathrm{ext}} / \mathrm{Sh}_{\mathrm{FD}, \mathrm{f}}$. The film length is $L_{\mathrm{f}}^{*}=1.96$ while Péclet number $(\mathrm{Pe})$ and non-dimensional film width $\left(W_{\mathrm{f}}^{*}\right)$ are varied. 


\section{List of Figures}

Fig. 1. (a) Dimensions of the simulated channel with uniformly spaced films; (b) Dimensions for the channel and bipolar plate cross section. The bipolar plate was not simulated.

Fig. 2. Film dimensions, TPCLs, contact angles and conventions of positioning which are shown from a) the top ( $z$ axis) and $b)$ the side ( $y$ axis) channel walls. (Long dashed lines: channel wall boundaries; Solid lines: TPCLs on the top and side channel wall; Dashed-dotted lines: TPCL on the GDL surface)

Fig. 3. Effect of film entrance types on local $\mathrm{Sh}\left(x_{\mathrm{f}}=5.00 \mathrm{~mm}\right)$.

Fig. 4. Characteristic points are shown in two scenarios of Sh profile due to a single film with zero length $\left(L_{\mathrm{f}}=\right.$ 0): a) No Sh overshoot, b) Overshoot of Sh.

Fig. 5. Characteristic points shown on a Sh profile due to a single film with a length larger than zero $\left(L_{\mathrm{f}}>0\right)$.

Fig. 6. Comparison of numerically generated $\mathrm{Sh}$ and predicted $\mathrm{Sh}$ through correlations $\left(\mathrm{Sh}_{\mathrm{cor}}\right)$ along the nondimensional distance measured in the film wake $\left(x_{\mathrm{w}}{ }^{*}\right)$. a) Superposition of $\mathrm{Sh}$ and $\mathrm{Sh}_{\mathrm{cor}}$, b) Ratio of $\mathrm{Sh}_{\mathrm{cor}} / \mathrm{Sh}$.

Fig. 7. The local ratio of correlation-predicted $\mathrm{Sh}\left(\mathrm{Sh}_{\text {cor }}\right)$ to numerically generated $\mathrm{Sh}: \mathrm{Sh}_{\mathrm{cor}} / \mathrm{Sh}$ for 3 consecutive films. The ratio is plotted against the distance measured from the first film in the domain $\left(x-x_{\mathrm{f}, 1}\right)$. At the same position, different data points are presented for various Pe and $W_{\mathrm{f}}^{*}$ conditions. $L_{\mathrm{f}}^{*}$ and $\Delta x_{\mathrm{f}}^{*}$ are $9.80(5.00 \mathrm{~mm})$.

Fig. 8. a) A water film $\left(W_{\mathrm{f}}=0.40 \mathrm{~mm}\right)$ visualized in an ex-situ fuel cell channel by Banerjee and Kandlikar [10]; b) The comparison of $\mathrm{Sh}_{\text {eff }}$ obtained through a numerical simulation and correlations. 


\begin{tabular}{ccccccccccc}
\hline$i\left[\mathrm{~A} \mathrm{~cm}^{-2}\right]$ & 0.10 & 0.20 & 0.30 & 0.40 & 0.50 & 0.70 & 0.80 & 1.00 & 1.20 & 1.50 \\
\hline$u_{\mathrm{m}}\left[\mathrm{m} \mathrm{s}^{-1}\right]$ & 1.59 & 2.12 & 3.18 & 4.24 & 5.30 & 7.41 & 8.48 & 10.59 & 12.72 & 15.89 \\
\hline $\mathrm{Pe}$ & 26.16 & 34.88 & 52.32 & 69.75 & 87.19 & 121.91 & 139.51 & 174.22 & 209.06 & 261.42 \\
\hline
\end{tabular}




\begin{tabular}{ccccc}
\hline$W_{\mathrm{f}}[\mathrm{mm}]$ & $F_{\text {ad,GDL }}$ & $F_{\text {ad,side }}$ & $F_{\text {ad,top }}$ & $F_{\text {ad }}$ \\
\hline 0.20 & 6.83 & 8.76 & 3.18 & 18.78 \\
0.25 & 8.55 & 8.47 & 3.97 & 20.99 \\
0.30 & 10.26 & 8.17 & 4.77 & 23.20 \\
0.35 & 11.98 & 7.87 & 5.56 & 25.41 \\
0.40 & 13.69 & 7.57 & 6.36 & 27.63 \\
0.45 & 15.40 & 7.27 & 7.15 & 29.83 \\
0.50 & 17.12 & 6.98 & 7.94 & 32.04 \\
\hline
\end{tabular}

-




\begin{tabular}{ccccccccc}
\hline$W_{\mathrm{f}}[\mathrm{mm}]$ & \multicolumn{1}{l}{$u_{\mathrm{m}}\left[\mathrm{m} \mathrm{s}^{-1}\right]$} \\
\cline { 2 - 9 } & 1.59 & 2.12 & 3.18 & 4.24 & 5.30 & 7.41 & 8.48 & 10.59 \\
\cline { 2 - 9 } 0.20 & 0.37 & 0.70 & 1.23 & 1.42 & 2.57 & 3.21 & 5.25 & 5.49 \\
0.25 & 0.72 & 1.06 & 1.88 & 2.86 & 4.00 & 6.73 & 8.31 & 11.90 \\
0.30 & 1.04 & 1.55 & 2.76 & 4.23 & 5.94 & 10.07 & 12.48 & 17.97 \\
0.35 & 1.48 & 2.21 & 3.96 & 6.10 & 8.61 & 14.68 & 18.22 & $\mathbf{2 6 . 3 5}$ \\
0.40 & 2.08 & 3.11 & 5.62 & 8.68 & 12.29 & 21.07 & 26.20 & $\mathbf{3 8 . 0 0}$ \\
0.45 & 2.93 & 4.39 & 7.96 & 12.33 & 17.50 & 30.10 & $\mathbf{3 7 . 4 9}$ & \\
0.50 & 4.16 & 6.23 & 11.35 & 17.62 & 25.06 & $\mathbf{4 3 . 2 1}$ & & \\
\hline
\end{tabular}




\begin{tabular}{cccccccc}
\hline$W_{\mathrm{f}}[\mathrm{mm}]$ & $u_{\mathrm{m}}[\mathrm{mm}]$ & & & & & & \\
\cline { 2 - 8 } & 1.59 & 2.12 & 3.18 & 4.24 & 7.41 & 10.59 & 15.89 \\
\cline { 2 - 8 } 0.20 & $\mathrm{x}$ & $\mathrm{x}$ & $\mathrm{x}$ & $\mathrm{x}$ & $\mathrm{x}$ & $\mathrm{x}$ & \\
0.30 & $\mathrm{x}$ & $\mathrm{x}$ & $\mathrm{x}$ & $\mathrm{x}$ & $\mathrm{x}$ & $\mathrm{x}$ & \\
0.40 & $\mathrm{x}$ & $\mathrm{x}$ & $\mathrm{x}$ & $\mathrm{x}$ & $\mathrm{x}$ & & \\
0.50 & $\mathrm{x}$ & $\mathrm{x}$ & $\mathrm{x}$ & $\mathrm{x}$ & & & \\
\hline
\end{tabular}

$W$
-1

$x+\frac{x}{x+2}$


Table5

\begin{tabular}{lccccc}
\hline$W_{\mathrm{f}}^{*}$ & \multicolumn{1}{l}{$\mathrm{Pe}$} & & & & \\
\cline { 2 - 6 } 0.39 & 26.16 & 69.75 & 121.91 & 174.22 & 261.42 \\
\cline { 2 - 6 } 0.59 & 0.78 & 0.82 & 0.85 & 0.88 & 0.92 \\
0.78 & 0.64 & 0.68 & 0.73 & $\mathbf{0 . 7 6}$ & \\
0.98 & 0.53 & 0.58 & $\mathbf{0 . 6 3}$ & & \\
\hline
\end{tabular}




\begin{tabular}{cccccc}
\hline$W_{\mathrm{f}}^{*}$ & $\mathrm{Pe}$ & & & & \\
\cline { 2 - 6 } & 26.16 & 69.75 & 121.91 & 174.22 & 261.42 \\
\hline 0.39 & 1.51 & 2.81 & 3.94 & 4.59 & 3.67 \\
0.59 & 1.99 & 4.47 & 4.80 & $\mathbf{1 . 1 3}$ & \\
0.78 & 2.48 & 5.33 & $\mathbf{1 . 5 1}$ & & \\
0.98 & 2.81 & 5.14 & & & \\
\hline
\end{tabular}

\section{Table6} $-2.81$

\begin{tabular}{cccccc}
\hline$W_{\mathrm{f}}^{*}$ & $\mathrm{Pe}$ & & & & \\
\cline { 2 - 6 } & 26.16 & 69.75 & 121.91 & 174.22 & 261.42 \\
\hline 0.39 & 1.51 & 2.81 & 3.94 & 4.59 & 3.67 \\
0.59 & 1.99 & 4.47 & 4.80 & $\mathbf{1 . 1 3}$ & \\
0.78 & 2.48 & 5.33 & $\mathbf{1 . 5 1}$ & & \\
0.98 & 2.81 & 5.14 & & & \\
\hline
\end{tabular}




Table7
\begin{tabular}{lllll} 
& & & \\
& & & & \\
\hline$W_{\mathrm{f}}{ }^{*}$ & 0.39 & 0.59 & 0.78 & 0.98 \\
\hline $\mathrm{Sh}_{\mathrm{FD}, \mathrm{f}}$ & 2.71 & 2.47 & 2.33 & 2.32 \\
\hline
\end{tabular}

.




\begin{tabular}{cccccc}
\hline$W_{\mathrm{f}}{ }^{*}$ & $\mathrm{Pe}$ & & & & \\
\cline { 2 - 6 } & 26.16 & 69.75 & 121.91 & 174.22 & 261.42 \\
\cline { 2 - 6 } 0.39 & 1.25 & 1.38 & 1.47 & 1.55 & 1.65 \\
0.59 & 1.43 & 1.66 & 1.85 & 2.00 & \\
0.78 & 1.58 & 1.95 & 2.25 & & \\
0.98 & 1.71 & 2.19 & & & \\
\hline
\end{tabular}

\section{Table8} 0.98 


\begin{tabular}{cccccc}
\hline$W_{\mathrm{f}}^{*}$ & $\mathrm{Pe}$ & & & & \\
\cline { 2 - 6 } & 26.16 & 69.75 & 121.91 & 174.22 & 261.42 \\
\cline { 2 - 6 } 0.39 & 1.05 & 1.13 & 1.18 & 1.23 & 1.29 \\
0.59 & 1.09 & 1.21 & 1.32 & 1.41 & \\
0.78 & 1.13 & 1.32 & 1.49 & & \\
0.98 & 1.18 & 1.41 & & & \\
\hline
\end{tabular}


Ėgure1

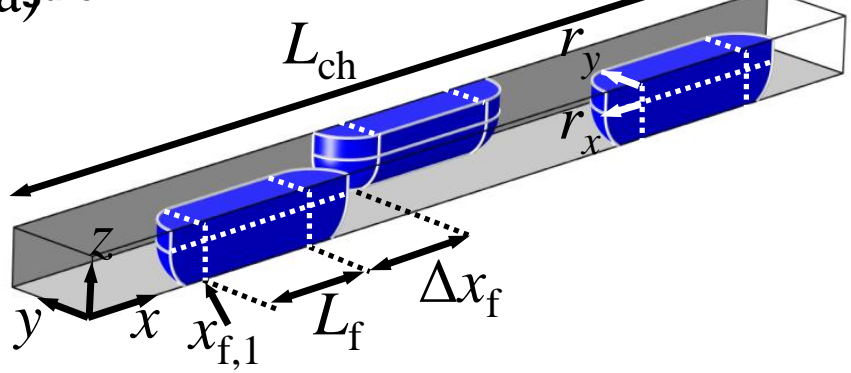

b)

Repeating Pattern
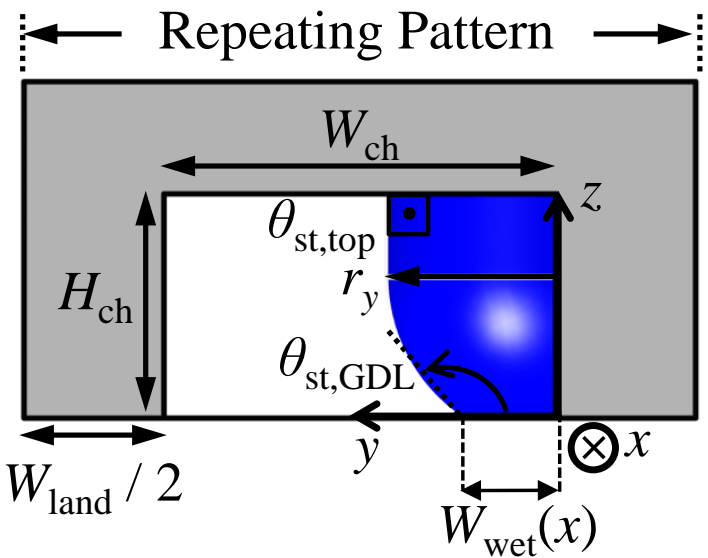
E)gurq2

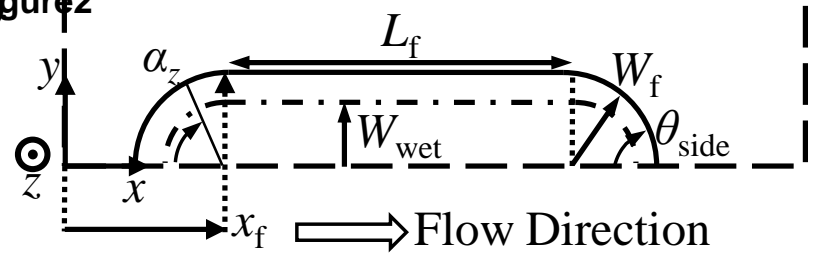

b)

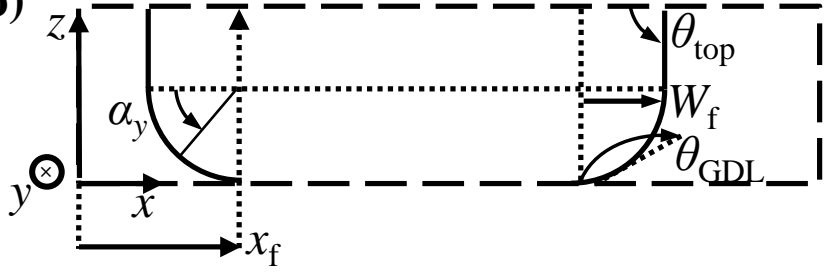




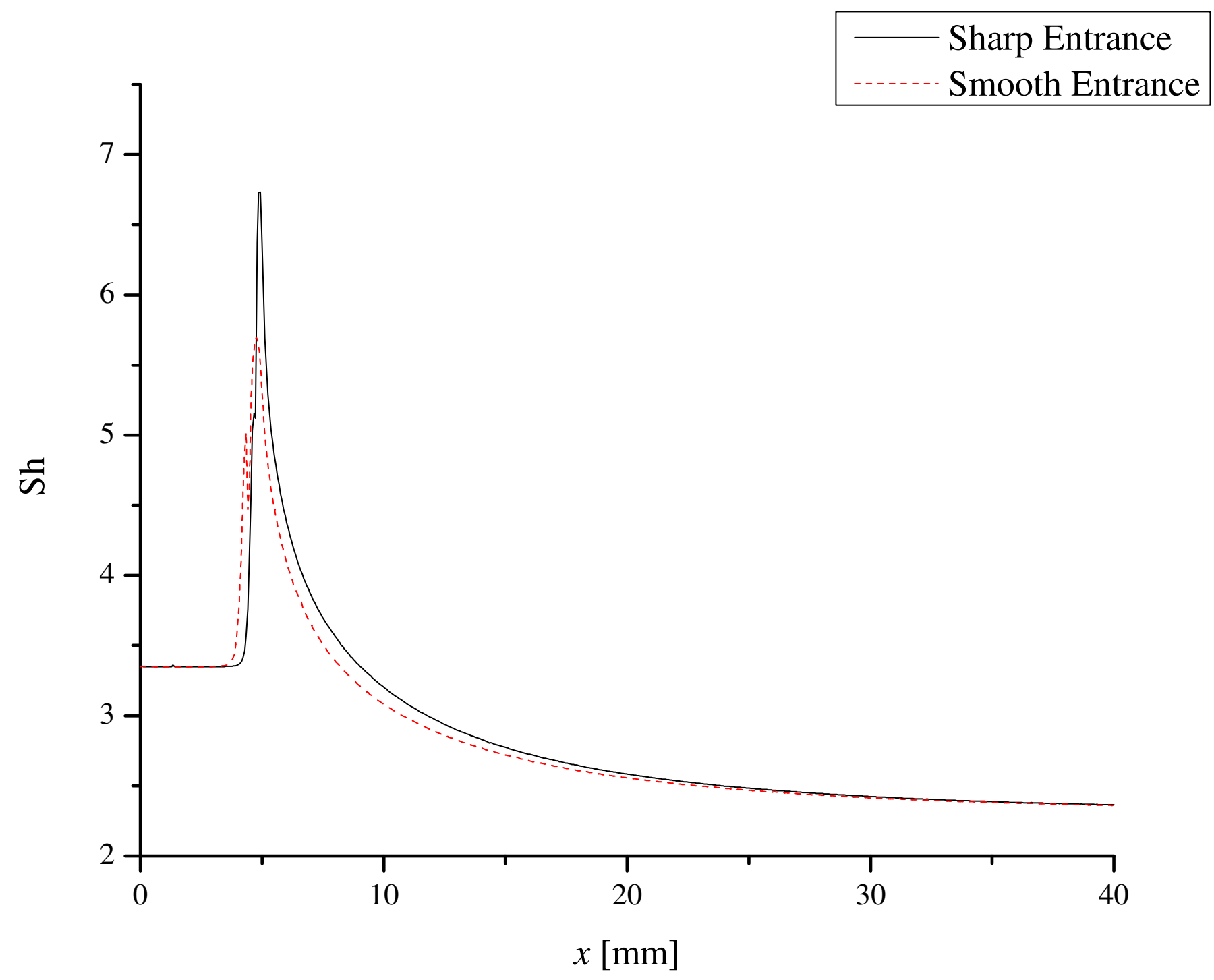




\section{f)gure4}

b)

$x_{\text {conv }} \operatorname{Sh}_{\mathrm{FD}_{\text {,ch }}}(1 \pm 0.01) \quad\left(x_{\max }, \mathrm{Sh}_{\max }\right)$

$\delta\left(x_{\min }, \mathrm{Sh}_{\min }\right)$

${ }^{10} x$

20

$\begin{array}{lll}0 & 10 & 20 \\ X & \end{array}$

10 


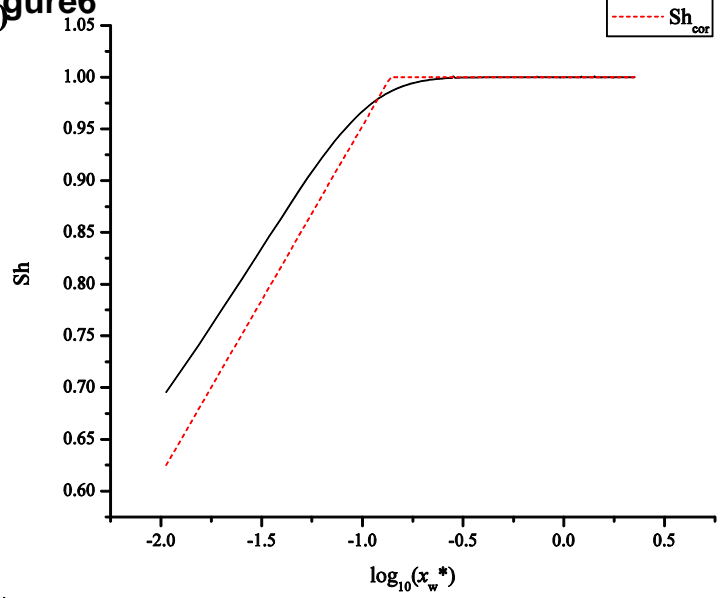

b)

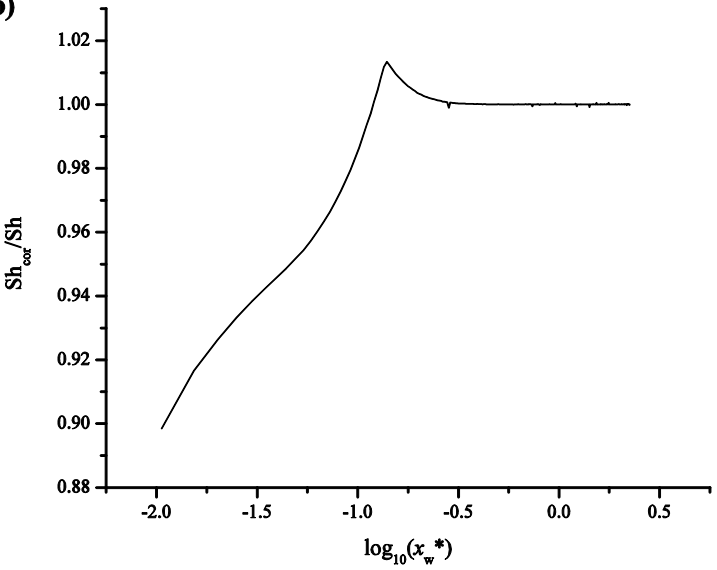




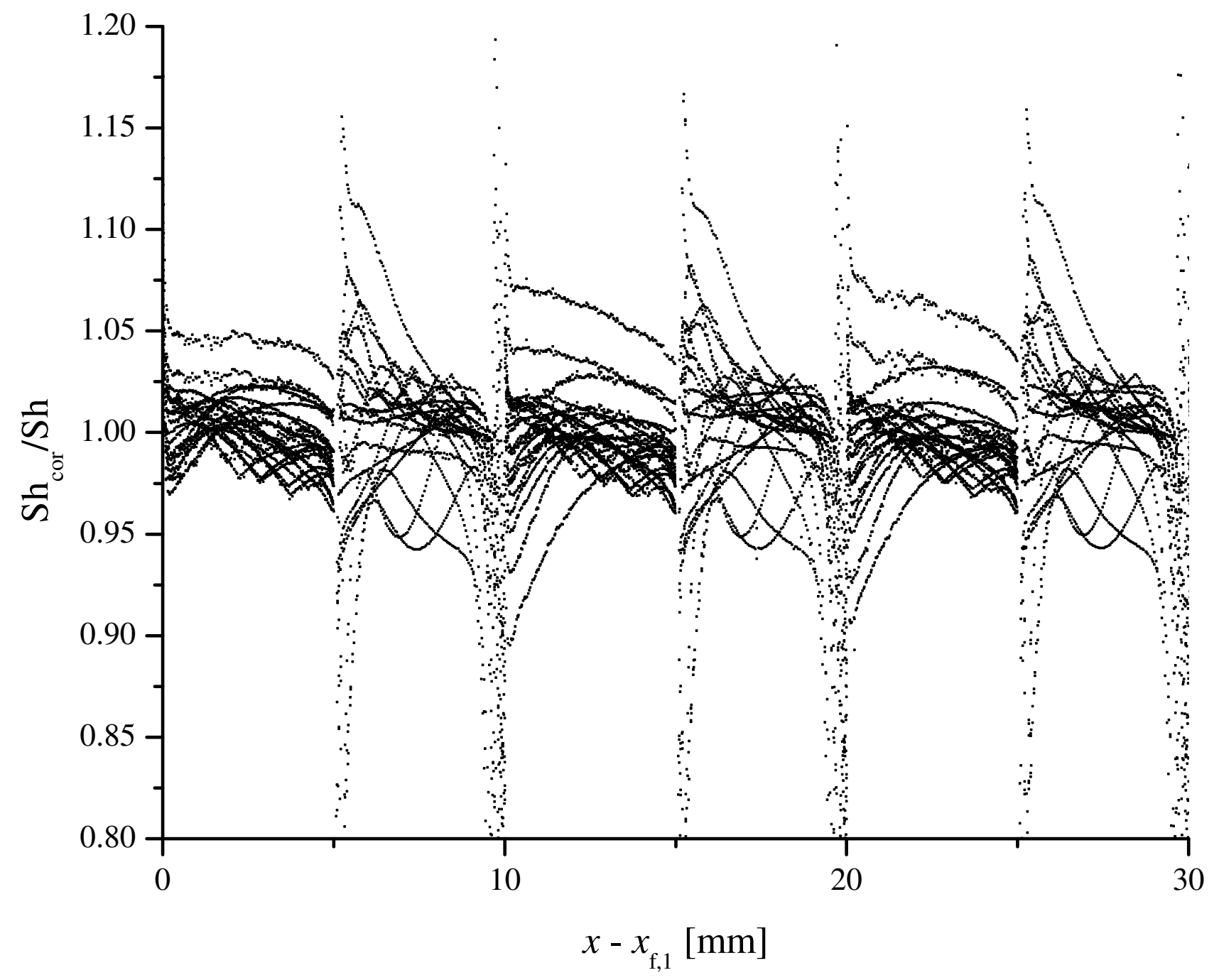




\section{Figure8 a)}

b)

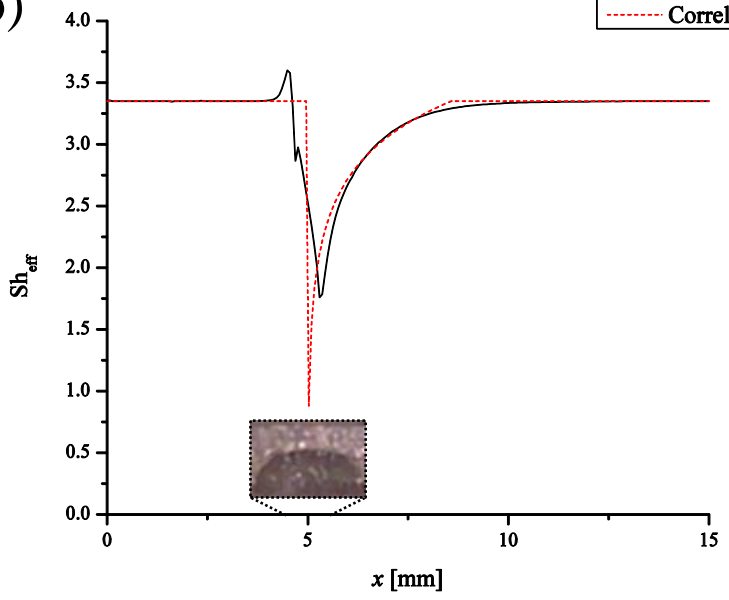

